\title{
Assessing human exposure risk and lung disease burden posed by airborne silver nanoparticles emitted by consumer spray products
}

This article was published in the following Dove Medical Press journal: International Journal of Nanomedicine

\section{Ying-Fei Yang \\ Wei-Ming Wang \\ Chi-Yun Chen \\ Tien-Hsuan Lu \\ Chung-Min Liao}

Department of Bioenvironmental Systems Engineering, National Taiwan University, Taipei, Taiwan I06I7,

Republic of China
Correspondence: Chung-Min Liao Department of Bioenvironmental Systems Engineering, National Taiwan University, No I, Sec 4, Roosevelt Road, Taipei, Taiwan I0617, Republic of China

Tel +88623634512

Email cmliao@ntu.edu.tw
Background: No systematic investigations have been conducted to assess the lung burden imposed by the chronic inhalation of silver nanoparticles (AgNPs) emitted by spray products. Objective: The objective of this study was to formulate a study framework that integrates a probabilistic risk assessment scheme with a mechanistic lung burden model for the estimation of health risks associated with the long-term inhalation of AgNP-containing spray products.

Materials and methods: A compartmentalized physiologically based alveolar deposition (PBAD) model was used to estimate AgNP lung burden. Dose-response relationships were established using nanotoxicity data sets obtained from rats (as a model organism). Weibull model-based thresholds of AgNP lung burden based on neutrophil-elevated inflammation biomarkers were estimated from Hill-based exposure-response relationships. Finally, the risks of lung disease posed by various AgNP-containing spray products were assessed.

Results: Conservative thresholds for the prevention of pulmonary disease were estimated as follows (mean $\pm \mathrm{SE}$ ): $34 \mathrm{~nm}$ AgNPs $(0.32 \pm 0.22 \mathrm{mg}$ ) and $60 \mathrm{~nm}$ AgNPs (1.08 $\pm 0.64 \mathrm{mg})$. Our results indicate that the risk probability was $\sim 0.5$ that the hazard quotient (HQ) estimates of deodorant with a count median diameter $(\mathrm{CMD}) \approx 30 \mathrm{~nm}$ exceeded 1 . The primary risk posed by AgNPs is transferred from the interstitial region to lymph nodes. Under the condition of $50 \%$ risk probability, the 97.5 percentile of HQ for the spray products were as follows: $\mathrm{CMD} \approx 30 \mathrm{~nm}$ $(\sim 3.4)$ and $\mathrm{CMD} \approx 60 \mathrm{~nm}(\sim 1.1)$.

Conclusion: Our application of the proposed risk assessment scheme to the results obtained in an in vivo animal model proved highly effective in elucidating the relationship between the characteristics of metallic NP-containing spray products and their corresponding toxicity. The integration of the proposed PBAD model with a risk assessment framework enables the rapid assessment of risk posed by spray products containing metallic NPs over various time scales. Keywords: silver nanoparticles, spray product, risk assessment, lung burdens, nanotoxicity

\section{Introduction}

Silver nanoparticles (AgNPs) are widely used for their antimicrobial effects; however, antimicrobial spray products (eg, deodorants [DO] and disinfectants [DI]) present an exposure risk via inhalation and dermal routes. It has been estimated that $\sim 14 \%$ of products containing AgNPs could potentially release airborne AgNPs into the air via dry powder dispersion. ${ }^{1}$ Dermal exposure has not been shown to cause DNA damage and/or inflammation in primary skin cells; however, the toxicity of inhaled AgNPs is yet to be fully elucidated. ${ }^{2}$ Hagendorfer et $\mathrm{al}^{3}$ reported that exposure to NPs via the respiratory tract poses the greatest risk, due to the direct exposure pathway and the large surface area of human lungs. 
Numerous studies have investigated the toxicity of inhaled AgNPs in vivo and in vitro. In vivo systems can be used to simulate exposure to AgNPs at higher frequencies and over longer durations. Foldbjerg et $\mathrm{al}^{4}$ reported DNA damage induced by reactive oxidative species (ROS) in a human alveolar cell line after acute exposure (24 hours) to AgNPs. Hyun et $\mathrm{al}^{5}$ reported the production of neutral mucin in lung tissue and foamy macrophages in alveolar tissue in rats exposed to AgNP aerosols for $6 \mathrm{~h}^{\text {day }}{ }^{-1}$ over a period of 28 days. Sung et $\mathrm{l}^{6}{ }^{6}$ reported dose-dependent chronic alveolar inflammation in rats exposed to airborne AgNPs for $6 \mathrm{~h} \mathrm{day}^{-1}$ over a period of 13 weeks.

Seiffert et $\mathrm{al}^{7}$ reported that AgNPs induced pulmonary eosinophilic and neutrophilic inflammation and bronchial hyper-responsiveness in rats. Minimal inflammation responses in lungs were also observed in mice repeatedly exposed to airborne AgNPs (3.3 $\mathrm{mg} \mathrm{m}^{-3}$ ) for $4 \mathrm{~h} \mathrm{day}^{-1}$ over a period of 10 days. ${ }^{8}$ Wijnhoven et $\mathrm{al}^{9}$ reported that the brain could be potentially exposed to airborne AgNPs due to AgNPs coming into contact with olfactory nerves during respiration.

The pulmonary toxicity of AgNPs has generally been explored using murine models; however, there is a dearth of information pertaining to the risk of humans inhaling AgNPcontaining spray products over extended time scales. In this study, we sought to overcome the limitations of in vitro and in vivo experiments in assessing the toxicity of airborne AgNPs under exposure durations comparable to the application scenarios typically encountered by humans. Most of the standard guidelines for nano-aerosols deal with workplace atmosphere, instrument setup, and measurement methods. ${ }^{10}$ Guidelines established by the Occupational Safety and Health Administration (OSHA) and National Institute for Occupational Safety and Health (NIOSH) deal exclusively with the occupational risks of exposure to airborne AgNPs. ${ }^{11,12}$

At present, there is a lack of rigorous air quality standards pertaining to AgNP aerosols and AgNP content in spray products. The only regulations on the use of antibacterial sprays were established by the Federal Insecticide, Fungicide Rodenticide Act in the USA ${ }^{13}$ and Biocide in the EU. ${ }^{14}$

In this study, we incorporated mechanistic modeling within a comprehensive risk assessment framework to derive appropriate threshold levels for AgNPs in spray products. Our objectives in this study were fivefold: 1) to predict the total lung burden posed by long-term exposure to AgNP-containing spray products; 2) to construct a dose-response profile for humans via extrapolation from exposure experiments on rats; 3) to derive AgNP lung burden threshold levels based on inflammation-related biomarker responses; 4) to evaluate the exceedance risks (ER) and risk quotients of lung burden imposed by AgNPs in the human body; and 5) to formulate an administrative strategy to minimize the risks associated with the long-term inhalation of AgNPs through the regulation of NP content in consumer spray products.

\section{Materials and methods Characterization of AgNP spray products}

Figure 1 presents the overall study framework, including the following: 1) problem identification (Figure 1A), 2) exposure analysis (Figure 1B), 3) effect analysis and threshold estimation (Figure 1C and D), and 4) risk characterization (Figure 1E).

In this study, we employed experimental data obtained by $\mathrm{Hsu}^{15}$ for the characterization of size-specific mass concentrations, AgNP content, and emissions of three commercial spray products. The spray products included one DI and two DO with AgNPs of different sizes. The DO with smaller NPs $(27.9-33.4 \mathrm{~nm})$ was designated as $\mathrm{DO}_{\mathrm{S}}$, whereas the DO with larger NPs $(57.3-61.5 \mathrm{~nm})$ was designated as $\mathrm{DO}_{\mathrm{L}}$. These measurements refer to the count median diameters (CMDs) of the AgNPs. The DI product employed a pump system, whereas the DO products employed a propellant. ${ }^{15}$ The AgNP aerosols were investigated using an electrical low pressure impactor (ELPI + TM, VeReference-1.2; Dekati Corp., Tempere, Finland) and a micro-orifice uniform deposit impactor.

The morphological features of the AgNPs were analyzed using a transmission electron microscope (TEM) equipped with a personal nanoparticle sampler developed by Hsu. ${ }^{15}$ Airflow into the sampling system for TEM analysis was controlled to $100 \mathrm{~L} \mathrm{~min}^{-1}$. The aerosol mass per press was as follows: $\mathrm{DI}\left(0.13 \mathrm{~g} \mathrm{press}^{-1}\right), \mathrm{DO}_{\mathrm{S}}\left(1.5 \mathrm{~g} \mathrm{press}^{-1}\right)$, and $\mathrm{DO}_{\mathrm{L}}$ $\left(1.3 \mathrm{~g} \mathrm{press}^{-1}\right)$. During measurements, we set the number of presses per use (PPU) higher for $\mathrm{DO}$ than for $\mathrm{DO}_{\mathrm{S}}$ and $\mathrm{DO}_{\mathrm{L}}$ to compensate for the lower aerosol mass per press.

Spray product usage was simulated under two scenarios: nonintensive and intensive. The number of PPU under nonintensive applications was as follows: $\mathrm{DI}(30), \mathrm{DO}_{\mathrm{S}}(10)$, and $\mathrm{DO}_{\mathrm{L}}(10)$. The number of PPU under intensive applications was as follows: DI (200), $\mathrm{DO}_{\mathrm{S}}(40)$, and $\mathrm{DO}_{\mathrm{L}}$ (40). The sampling duration under each scenario was 40 minutes. ${ }^{15}$

\section{Physiochemical characterization of AgNPs} The size distribution of AgNPs from the three spray products was not measured; however, the aggregation of AgNPs from $\mathrm{DO}_{\mathrm{S}}$ and $\mathrm{DO}_{\mathrm{L}}$ was observed in TEM images. ${ }^{15}$ The dynamic behavior of the AgNPs from the three spray 


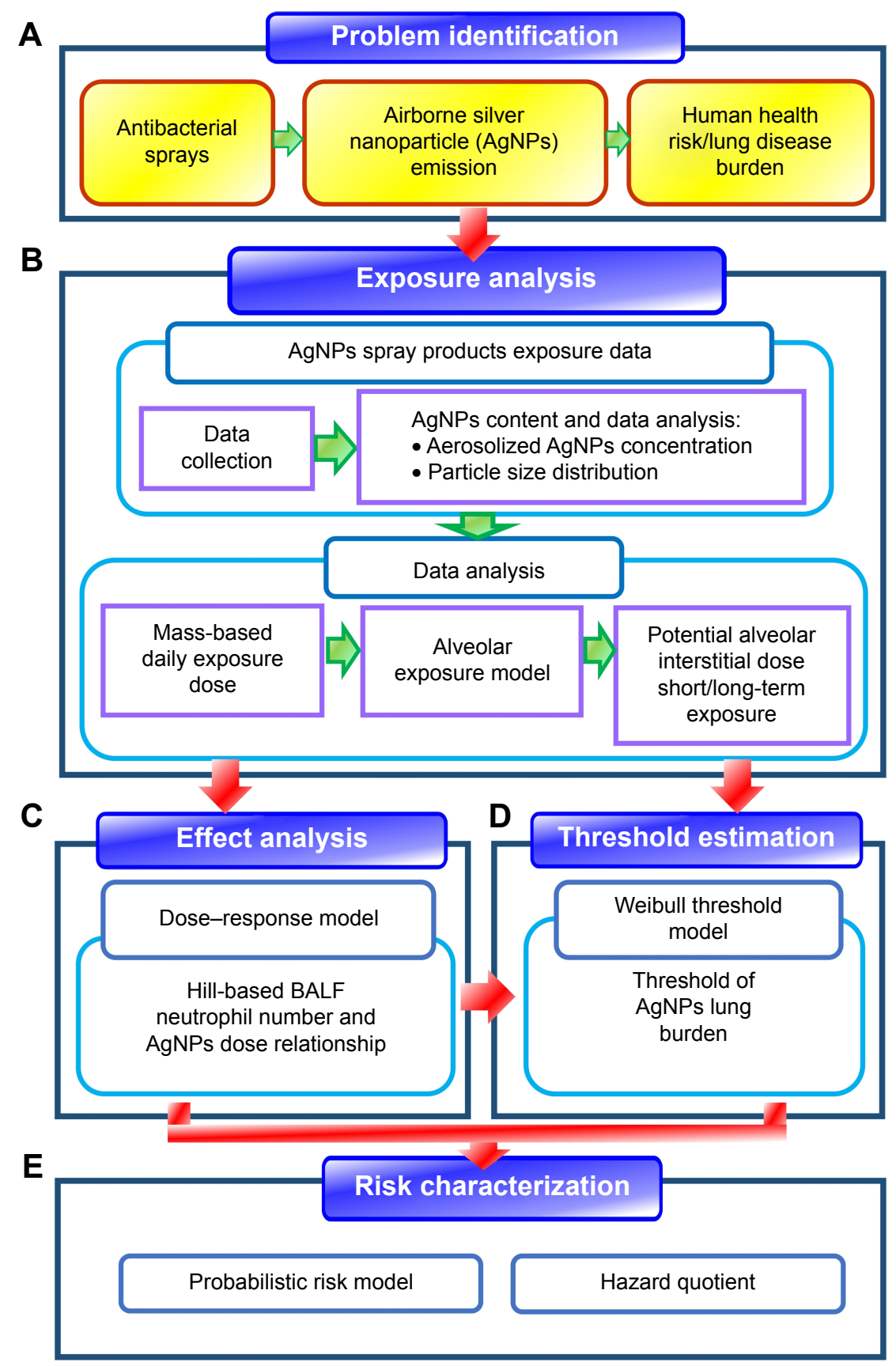

Figure I Schematic showing the overall study framework.

Notes: (A) Problem formulation of human health risk or lung burdens posed by exposures of airborne AgNPs emitted from spray products, (B) exposure analysis of mass concentrations and particle size distributions of aerosolized AgNPs, (C) effect analysis of relationship between BALF neutrophil number and AgNPs dose in human lung, (D) threshold estimation of AgNPs lung burdens, and (E) risk characterization of airborne AgNPs toxicities in human lung. Abbreviation: BALF, bronchoaveolar lavage fluid.

products was elucidated by recompiling the number concentrations released by the spray products and the Ag contents within various size ranges (Figure S1; Table S1). ${ }^{15}$ Most of the AgNPs in the three spray products were transported in aerosols exceeding $100 \mathrm{~nm}$ (Table S1). ${ }^{15}$ To further elucidate the contents of the aerosols from the three spray products, we also compiled the results of the energy dispersive X-ray (EDX) analyses by selecting representative TEM images of aerosols (Table S2). ${ }^{15}$

\section{Alveolar deposition model}

We employed the compartmentalized physiologically based alveolar deposition (PBAD) model developed by Kuempel et $\mathrm{al}^{16,17,19}$ and Tran et al ${ }^{18}$ to mechanistically estimate the human lung burden imposed by AgNPs. The PBAD model can be used to predict the long-term burden by considering clearance processes in the pulmonary region and mechanisms of particle distribution mediated by alveolar macrophages. In the PBAD model, the human lung was divided into four 


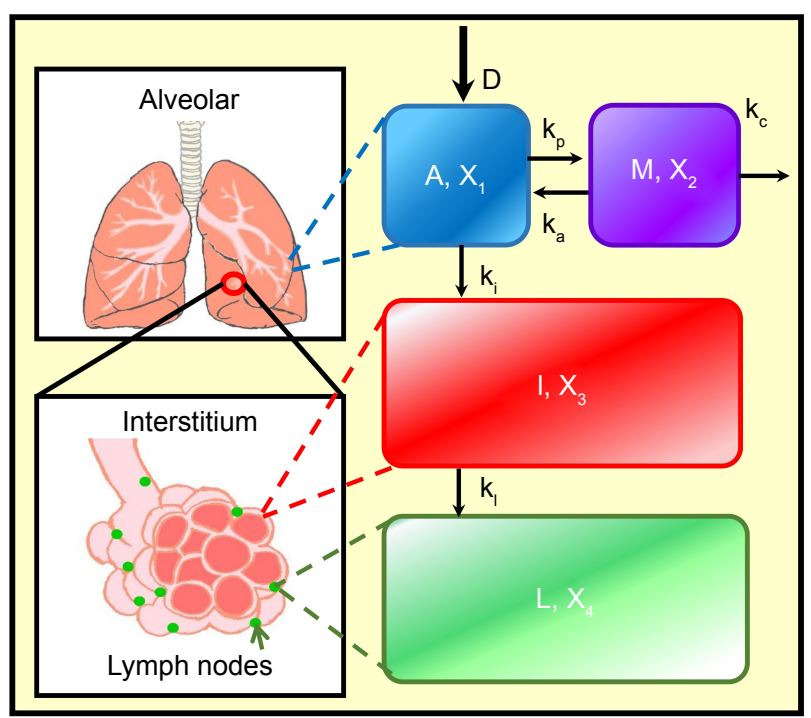

Figure 2 Schematic showing the compartmentalized PBAD model.

Abbreviations: PBAD, physiologically based alveolar deposition; A, alveolar region; $M$, alveolar macrophage region; I, interstitial region; L, lymph node region; $X_{1}$, AgNPs in alveolar region; $X_{2}$, AgNPs in alveolar macrophage; $X_{3}$, AgNPs in interstitial region; $\mathrm{X}_{4}, \mathrm{AgNPs}$ in lymph node region; $\mathrm{k}_{\mathrm{i}}$, transfer rate of AgNPs from alveolar region to interstitial region; $k_{1}$, transferred rate of AgNPs from interstitial region to lymph node; $k_{p}$, phagocytosis rate of macrophage; $k_{a}$, apoptosis rate of macrophage; $k_{c}$, physical clearance rate of AgNPs; AgNP, silver nanoparticle.

regions: alveolar surface, alveolar macrophage, interstitium, and lymph nodes (Figure 2). A first-order four-compartment PBAD model was used to simulate the input and output conditions, which largely determine the accumulation of AgNPs in human lungs. The results were derived as dynamic lung burden and biokinetic reaction rates in various compartments. This made it possible to mechanistically explore biodynamic interactions among the various compartments using a set of ordinary differential equations (Table 1).

When aerosols are inhaled (ie, access the respiratory tract), AgNPs are deposited in the alveolar region at a specific deposition fraction (Eqs. (T1) and (T2); Table 1) where C refers to the mass concentration of AgNP-containing aerosols $\left(\mu \mathrm{g} \mathrm{m}^{-3}\right), \mathrm{DF}(-)$ is the deposition fraction dependent on particle size (nm), ED is the exposure duration based on previous surveys of AgNP spray products (140 minutes), ${ }^{20,21}$ and BR is the typical breathing rate in Taiwan $\left(0.38 \pm 0.07 \mathrm{~m}^{3} \mathrm{~h}^{-1}\right){ }^{22}$

Note that AgNPs could be transformed into other chemical forms (eg, Ag ions or Ag oxides) during the course of exposure. Nonetheless, most of the Ag particles that access alveolar regions (regardless of chemical makeup) would be at the nanoscale, due to the fact that the CMDs of all three spray products are below $100 \mathrm{~nm}$ (Table 1). Thus, the Ag particle content in the PBAD model simulations is expressed as AgNP lung burden.

AgNPs deposited in the alveolar region are either translocated into interstitial areas or phagocyted by macrophages.
These processes are expressed using Eq. (T3) (Table 1), where $t$ refers to the duration of exposure (days), $X_{1}(t)$ and $\mathrm{X}_{2}(\mathrm{t})$, respectively, refer to the time-dependent AgNP dose in alveolar and macrophage regions (measured in $\mathrm{mg}$ ), $\mathrm{k}_{\mathrm{p}}$ is the rate of phagocytosis by macrophage $\left(\right.$ day $\left.^{-1}\right), \mathrm{k}_{\mathrm{i}}$ is the rate of AgNP transfer from alveolar to interstitial regions $\left(\right.$ day $\left.^{-1}\right)$, and $\mathrm{k}_{\mathrm{a}}$ is the rate of macrophage apoptosis $\left(\mathrm{day}^{-1}\right)$. During the transfer from alveolar to macrophage regions, many AgNPs are eliminated from the lungs. This is expressed using Eq. (T4) (Table 1), where $\mathrm{k}_{\mathrm{c}}$ refers to the physical clearance rate of AgNPs $\left(\right.$ day $\left.^{-1}\right)$.

The dynamic deposition of AgNPs in interstitial regions is expressed using Eq. (T5), where $\mathrm{X}_{3}(\mathrm{t})$ refers to the timedependent dose of AgNPs in the interstitial region, and $\mathrm{k}_{1}$ is the rate at which AgNPs are transferred from interstitial to lymph node regions $\left(\right.$ day $\left.^{-1}\right)$ (Table 1$)$. Total AgNP deposition was estimated by summing the doses of AgNPs in the alveolar, macrophage, and interstitial regions using Eq. (T6) (Table 1). The deposition of AgNPs in the lymph node region was described using Eq. (T7), where $X_{4}(t)$ refers to the time-dependent dose of AgNPs in the lymph node region (mg) (Table 1). Table 1 lists the range of values applied to each rate parameter $\left(\mathrm{k}_{\mathrm{p}}, \mathrm{k}_{\mathrm{c}}, \mathrm{k}_{\mathrm{a}}, \mathrm{k}_{\mathrm{i}}\right.$, and $\left.\mathrm{k}_{\mathrm{l}}\right)$ in implementing the PBAD model.

\section{Dose-response model}

We sought to match as closely as possible the size ranges of AgNPs in the spray products in this study by using AgNPs of 34 and $60 \mathrm{~nm}$ for the construction of a dose-response model to characterize the lung burden imposed by AgNPs in the human body vs the increase in the number of neutrophils. This was achieved by fitting the three-parameter Hill model $^{23}$ to published datasets. ${ }^{24}$ We adopted the number of neutrophils isolated from bronchoaveolar lavage fluid (BALF) exposed to aerosolized AgNPs as the biomarker presenting the highest sensitivity to inflammation in male Fischer rats (F344/DuCrl). ${ }^{24}$

The dose-response profile illustrating the relationship between AgNP lung burden and neutrophil increment can be written as follows:

$$
\mathrm{E}(\mathrm{C})=\frac{\mathrm{E}_{\text {max }}}{1+\left(\frac{\mathrm{EC} 50}{\mathrm{C}}\right)^{\mathrm{n}}}
$$

where $\mathrm{C}$ refers to the lung burden imposed by AgNPs (mg), $\mathrm{E}_{\max }$ is the maximum increase in the number of neutrophils (-fold), EC50 is the dose with an effect equal to $50 \% \mathrm{E}_{\max }$ $(\mathrm{mg})$, and $\mathrm{n}$ is the fitted Hill coefficient, such that $\mathrm{n}=1$ 
Table I Equations for compartmentalized PBAD model along with used values of rate parameters

\begin{tabular}{|c|c|c|}
\hline Interpretation & Equations $^{a}$ & \\
\hline Mass-based dosimetric exposure model & $\mathrm{D}=\mathrm{C} \times \mathrm{DF} \times \mathrm{ED} \times \mathrm{BR}$ & $(\mathrm{TI})$ \\
\hline $\begin{array}{l}\text { Silver deposition fraction in alveolar-interstitial } \\
\text { region }\end{array}$ & $D F=\left(\frac{0.0155}{d_{p}}\right)\left[\exp \left(-0.416\left(\ln d_{p}+2.84\right)^{2}\right)+19.11 \exp \left(-0.482\left(\ln d_{p}-1.362\right)^{2}\right)\right]$ & $(\mathrm{T} 2)$ \\
\hline AgNPs dose $(\mathrm{mg})$ in alveolar region $\mathrm{A}: \mathrm{X}_{1}$ & $\frac{d X_{1}(t)}{d t}=D-k_{P} X_{1}(t)-k_{i} X_{1}(t)+k_{a} X_{2}(t)$ & (T3) \\
\hline AgNPs dose in alveolar macrophage region $M: X_{2}$ & $\frac{d X_{2}(t)}{d t}=k_{p} X_{1}(t)-k_{c} X_{2}(t)-k_{a} X_{2}(t)$ & (T4) \\
\hline AgNPs dose in interstitial region I: $X_{3}$ & $\frac{d X_{3}(t)}{d t}=k_{i} X_{1}(t)-k_{1} X_{3}(t)$ & (T5) \\
\hline Total AgNPs deposition, $X$ & $X(t)=X_{1}(t)+X_{2}(t)+X_{3}(t)$ & (T6) \\
\hline AgNPs dose in lymph node region $\mathrm{L}: \mathrm{X}_{4}$ & $\frac{\mathrm{dX}_{4}(\mathrm{t})}{\mathrm{dt}}=\mathrm{k}_{1} \mathrm{X}_{3}(\mathrm{t})$ & (T7) \\
\hline Rate parameter & Value $\left(\right.$ day $\left.^{-1}\right)$ & \\
\hline $\begin{array}{l}k_{p} \\
k_{c} \\
k_{a} \\
k_{i} \\
k_{1}\end{array}$ & $\begin{array}{l}0.996(0-0.996))^{\mathrm{a}, \mathrm{b}} \\
1.50 \times 10^{-3}\left(1.10 \times 10^{-4}-4.40 \times 10^{-3}\right)^{\mathrm{a}, \mathrm{c}} \\
3.30 \times 10^{-2 b} \\
0.42943(0.42939-0.42946)^{\mathrm{a}, \mathrm{d}} \\
3.75 \times 10^{-3}\left(2.74 \times 10^{-3}-3.90 \times 10^{-3}\right)^{\mathrm{a}, \mathrm{d}}\end{array}$ & \\
\hline
\end{tabular}

Notes: aMin-max. 'Data from Tran et al. ${ }^{18}$ cData from Kuempel et al. ${ }^{16}$ dData from Takenaka et al. ${ }^{42}$

Abbreviations: PBAD, physiologically based alveolar deposition; A, alveolar region; BR, breathing rate; DF, AgNPs deposition fraction in alveolar-interstitial region; ED, exposure duration; I, interstitial region; L, lymph node region; $M$, alveolar macrophage region; $k_{a}$, apoptosis rate of macrophage; $k_{c}$, physical clearance rate of nanoparticle; $k_{i}$, transferred rate of AgNPs from alveolar region to interstitial region; $k_{1}$, transferred rate of AgNPs from interstitial region to lymph node; $k_{p}$, phagocytosis rate of macrophage; C, mass concentration of AgNPs aerosols $\left(\mu \mathrm{g} \mathrm{m}^{-3}\right)$; AgNP, silver nanoparticle.

indicates a linear response (according to the MichaelisMenten model) and $\mathrm{n}>1$ indicates that the biomarker is ultrasensitive to the toxicant. To identify the AgNP lung burden that induces an inflammatory response, we also estimated the $\mathrm{EC} 10, \mathrm{EC} 5$, and $\mathrm{EC} 1$ resulting in $10 \%, 5 \%$, and $1 \% \mathrm{E}_{\max }$.

\section{Predictive risk threshold}

A three-parameter Weibull threshold model was used to obtain the best fit for EC10, EC5, and EC1 toxicity data in estimating the threshold lung burden of AgNPs for the prevention of pulmonary disease. EC10, EC5, and EC1 toxicity data were adopted from the estimated EC10, EC5, and EC1 cumulative distribution functions (CDFs) obtained using the Hill-based dose-response model in Eq. (1) for the probabilistic fitting of experimental data. ${ }^{24}$

The Weibull threshold model can be expressed as follows:

$$
\mathrm{F}(\mathrm{C})=1-\exp \left[-\left(\frac{\mathrm{C}-\gamma}{\alpha}\right)^{\beta}\right], \mathrm{C}>\gamma>0, \alpha>0, \beta>0
$$

where $\mathrm{F}(\mathrm{C})$ represents the $\mathrm{EC} 10, \mathrm{EC} 5$, and $\mathrm{EC} 1 \mathrm{CDF}$ data corresponding to specific AgNP lung burden values in the human body, $\alpha$ is the scale parameter affecting distribution of $\mathrm{F}(\mathrm{C})$ as a change in the abscissa scale, $\beta$ is the shape parameter representing the slope of the line in the CDF data, and $\gamma$ is the fitted threshold dose (mg), also denoted as predicted no-effect concentration.

The Weibull threshold model was used to obtain the best fit for the $2.5,5,50,95$, and 97.5 percentiles in $\mathrm{CDF}$ data extracted from EC10, EC5, and EC1, resulting in the following threshold burdens: $\gamma_{10}, \gamma_{5}$, and $\gamma_{1}$.

\section{Probabilistic risk model}

Our underlying objective in this study was to protect users of AgNP-containing sprays from the effects of pulmonary disease resulting from exposure to aerosolized AgNPs. Threshold level $\gamma_{1}$ was selected as a conservative criterion for the characterization of risk with the aim of preventing pulmonary disease. We developed a probabilistic risk assessment model linking the PBAD model with the Hill-based dose-response model to characterize the dose-response relationship between AgNP-derived lung burden and the incremental increase in neutrophil count following exposure to aerosolized AgNPs.

In accordance with Bayesian inference, the cumulative risk of neutrophil increases under a given AgNP lung burden 
$(\mathrm{R}(\mathrm{E}))$ (ie, posterior probability) is the product of a prior probability $\mathrm{P}(\mathrm{C})$ and a conditional probability function (ie, likelihood) $\mathrm{P}(\mathrm{E} \mid \mathrm{C})$, which can be expressed as follows:

$$
R(E)=P(C) \times P(E \mid C)
$$

where

$$
\mathrm{P}(\mathrm{E} \mid \mathrm{C})=\Phi\left(\frac{\mathrm{E}_{\max }}{1+\left(\frac{\mathrm{EC} 50}{\mathrm{C}}\right)^{\mathrm{n}}}\right)
$$

It is then possible to derive exceedance profiles as $1-\mathrm{R}(\mathrm{E})$, otherwise known as the ER.

To assess the potential risk to human health, we characterized the increase in the number of neutrophils as an effect of inflammation induced by AgNPs using the hazard quotient (HQ) model, as follows:

$$
\mathrm{HQ}=\frac{\mathrm{C}}{\gamma_{1}}
$$

where $\mathrm{C}$ and $\gamma_{1}$ are estimated probabilistically. HQ $>1$ implies that AgNP-induced lung burden poses a potential risk to human health based on neutrophil expression, whereas HQ $<1$ indicates that AgNP-induced lung burden poses no risk to human health. To perform a reasonable assessment of risk from the three products in this study, we estimated the risks associated with the inhalation of spray $\mathrm{DO}_{\mathrm{S}}$ and $\mathrm{DO}_{\mathrm{L}}$ only, because the shape of the AgNPs in DI was inconsistent with the shape of AgNPs in dose-response analysis. ${ }^{24} \mathrm{We}$ also estimated threshold exposure durations of $\mathrm{DO}_{\mathrm{S}}$ and $\mathrm{DO}_{\mathrm{L}}$ based on the threshold dose estimates obtained under the condition that $\mathrm{HQ}=1$.

\section{Uncertainty and data analysis}

Simulations of the PBAD model were conducted using Berkeley Madonna 8.0.1, which was developed by Robert Macey and George Oster at the University of California, Berkeley. TableCurve 2D (Version 5.01; AISN Software, Mapleton, OR, USA) was used for mathematical model fittings. Monte Carlo (MC) analysis was used to obtain 2.5 and 97.5 percentiles as 95\% CIs for all assessments of uncertainty. We also performed sensitivity analysis to identify the PBAD model parameters with the most pronounced effect on AgNP lung burden in the human body.
We performed parameterization and sensitivity analysis of variables using 10,000 MC simulations, implemented on Crystal Ball software (Version 2000.2; Decisioneering, Denver, CO, USA).

\section{Results}

\section{Estimating size distribution and mass concentration of aerosols}

Figure 3 presents the size distribution and estimated mass concentrations of aerosols from three AgNP-containing spray products under non-intensive and intensive applications. The size distributions of the aerosols from each of the products were well fitted to the lognormal (LN) function $\left(r^{2}=0.67-0.99\right.$ with $\left.P<0.01\right)$, regardless of whether applied intensively or non-intensively. Under non-intensive applications, the estimated mass geometric mean diameters (GMDs) and geometric standard deviations (GSDs) were as follows: DI $(1.78 \mu \mathrm{m} \pm 1.34), \mathrm{DO}_{\mathrm{S}}$ $(1.94 \mu \mathrm{m} \pm 3.82)$, and $\mathrm{DO}_{\mathrm{L}}(0.48 \mu \mathrm{m} \pm 3.90)$ (Figure $3 \mathrm{~A}$, $\mathrm{C}$, and $\mathrm{E}$ ).

Under non-intensive applications, the estimated mass GMDs and GSDs were as follows: DI (1.87 $\mu \mathrm{m} \pm$ 1.34), $\mathrm{DO}_{\mathrm{S}}(2.09 \mu \mathrm{m} \pm 5.88)$, and $\mathrm{DO}_{\mathrm{L}}(0.34 \mu \mathrm{m} \pm 5.15)$ (Figure 3B, D, and F). The estimated mass concentrations of aerosols in non-intensive applications were as follows: DI (43.96 $\mu \mathrm{g} \mathrm{m}^{-3}$ [95\% CI: 36.96-50.96]), $\mathrm{DO}_{\mathrm{S}}\left(118.80 \mu \mathrm{g} \mathrm{m}^{-3}\right.$ [100.87-136.74]), and $\mathrm{DO}_{\mathrm{L}}\left(139.99 \mu \mathrm{g} \mathrm{m}^{-3}\right.$ [138.24-141.74]) (Figure 3A, C, and E).

The estimated mass concentration of aerosols in intensive applications were as follows: DI $\left(611.04 \mu \mathrm{g} \mathrm{m}^{-3}\right), \mathrm{DO}_{\mathrm{S}}$ $\left(1,504.74 \mu \mathrm{g} \mathrm{m}^{-3}\right)$, and $\mathrm{DO}_{\mathrm{L}}\left(4,051.50 \mu \mathrm{g} \mathrm{m}^{-3}\right.$ ) (Figure 3B, D, and $\mathrm{F}$ ). The measured AgNP contents in aerosols in intensive applications were as follows: DI (4.59\%), $\mathrm{DO}_{\mathrm{S}}(0.60 \%)$, and $\mathrm{DO}_{\mathrm{L}}(0.37 \%)$, which indicated the following mean AgNP mass concentrations: DI $\left(2.02 \mu \mathrm{g} \mathrm{m}^{-3}\right), \mathrm{DO}_{\mathrm{S}}\left(0.71 \mu \mathrm{g} \mathrm{m}^{-3}\right)$, and $\mathrm{DO}_{\mathrm{L}}\left(0.52 \mu \mathrm{g} \mathrm{m}^{-3}\right)$ (Figure $3 \mathrm{~A}, \mathrm{C}$, and $\mathrm{E}$ ). The measured AgNP contents in aerosols in intensive applications were as follows: $\mathrm{DI}(4.64 \%), \mathrm{DO}_{\mathrm{S}}(0.58 \%)$, and $\mathrm{DO}_{\mathrm{L}}(0.57 \%)$, which indicated the following mean AgNP mass concentrations: DI $\left(28.35 \mu \mathrm{g} \mathrm{m}^{-3}\right), \mathrm{DO}_{\mathrm{S}}\left(8.73 \mu \mathrm{g} \mathrm{m}^{-3}\right)$, and $\mathrm{DO}_{\mathrm{L}}\left(23.09 \mu \mathrm{g} \mathrm{m}^{-3}\right)$ (Figure 3B, D, and F).

On the other hand, size distributions as function of number concentrations of AgNP-containing aerosols from three spray products were also re-analyzed (Figure S1). ${ }^{15}$ The LN function well fitted to the size distributions of aerosols ( $r^{2}=0.99$ with $P<0.01$ ). The GMDs were $0.016,0.002$, and 0.003 with GSDs of $1.90,1.29$, and 2.37 in spray DI, $\mathrm{DO}_{\mathrm{S}}$, and $\mathrm{DO}_{\mathrm{L}}$, respectively ( Figure $\left.\mathrm{S} 1\right)$. 
Non-intensive

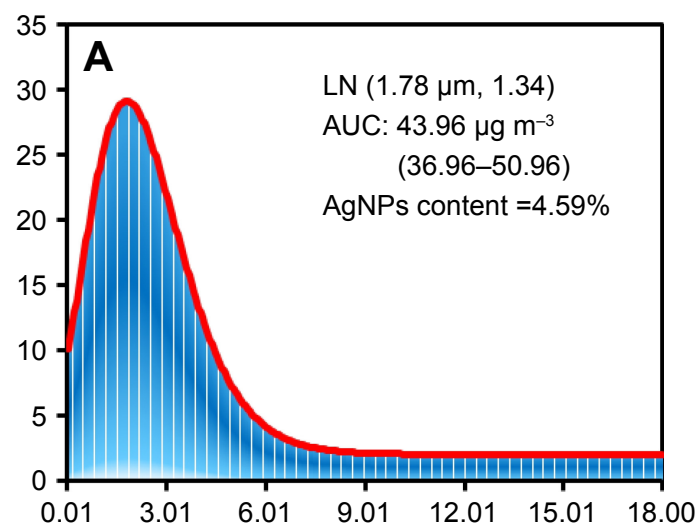

Spray DI

Intensive

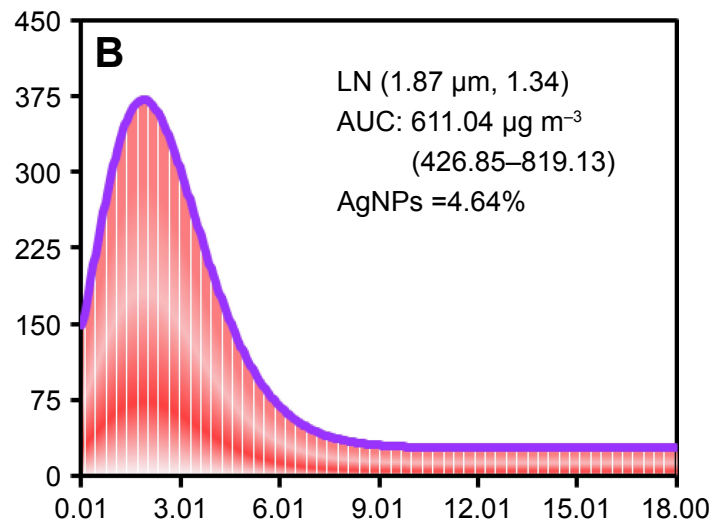

Spray $\mathrm{DO}_{\mathrm{s}}$
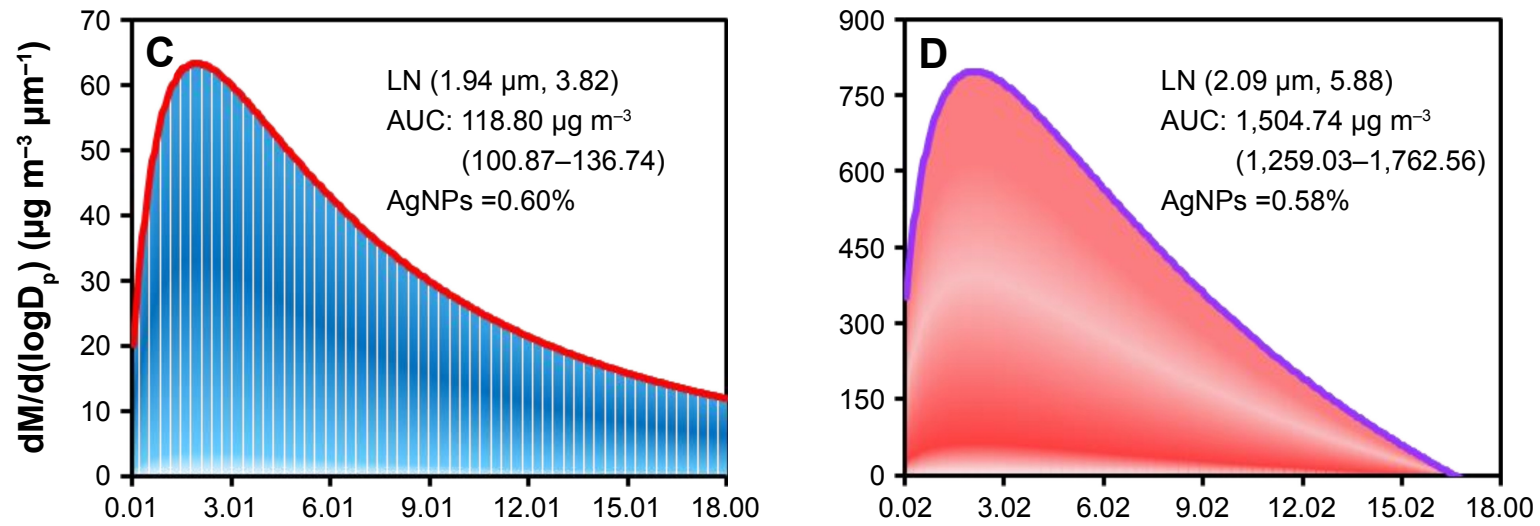

Spray $\mathrm{DO}_{\mathrm{L}}$
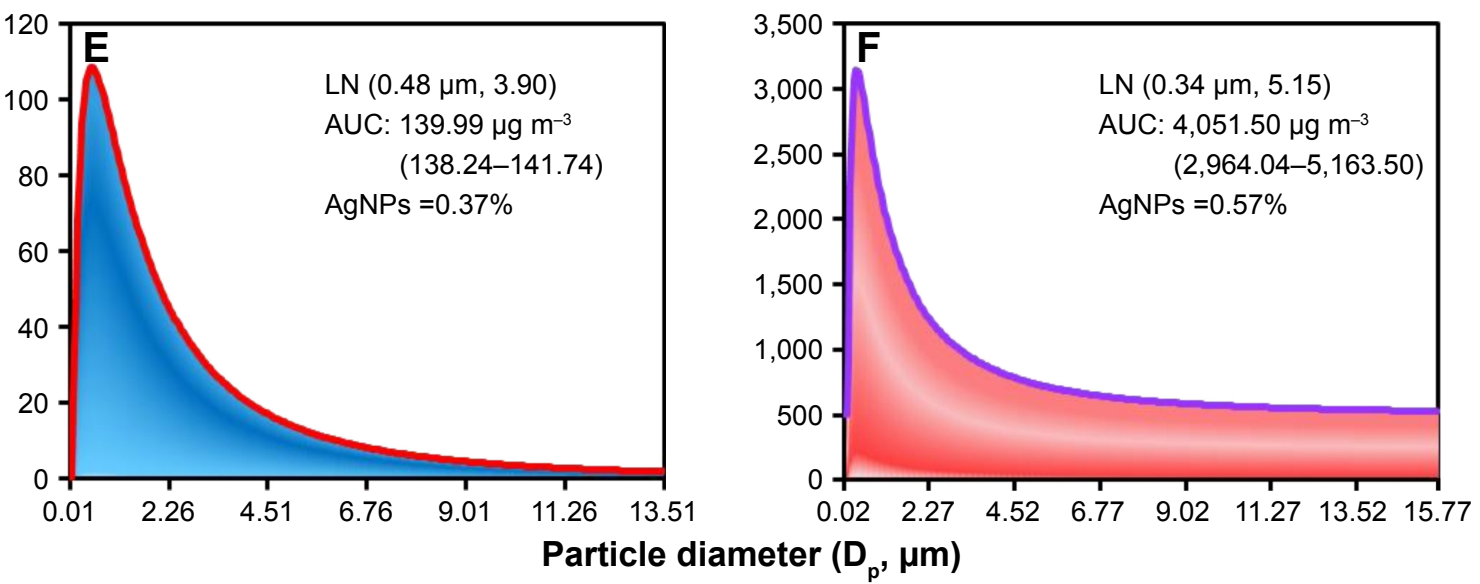

Figure 3 Estimated mass concentrations of aerosols based on size distributions of droplets in spray $(\mathbf{A}, \mathbf{B}) \mathrm{DI},(\mathbf{C}, \mathbf{D}) \mathrm{DO}_{S}$, and $(\mathbf{E}, \mathbf{F}) \mathrm{DO}_{L}$ in non-intensive or intensive application. Abbreviations: DI, disinfectant; $\mathrm{DO}_{\mathrm{s}}$, deodorant of $\mathrm{AgNPs}$ in smaller scales; $\mathrm{DO}_{\mathrm{L}}$, deodorant of $\mathrm{AgNPs}$ in larger scales; LN, lognormal; $\mathrm{AUC}$, area under the curve; $\mathrm{AgNP}$, silver nanoparticle.

\section{Lung deposition analysis}

In exploring the long-term risks associated with the inhalation of AgNP-containing spray products, we made predictions pertaining to the accumulation of AgNPs in the alveolar, macrophage, interstitial, and lymph node regions under chronic exposure (non-intensive and intensive) over a period of 2 years (Figures 4 and $\underline{\mathrm{S} 2}$ ). Overall, the total AgNP-induced lung burden and accumulation of AgNPs reached the point of saturation in the alveolar, macrophage, and interstitial regions under non-intensive as well as intensive applications (Figures 4 and $\underline{\mathrm{S} 2}$ ). After 2-year exposure, the non-intensive application of DI would result 

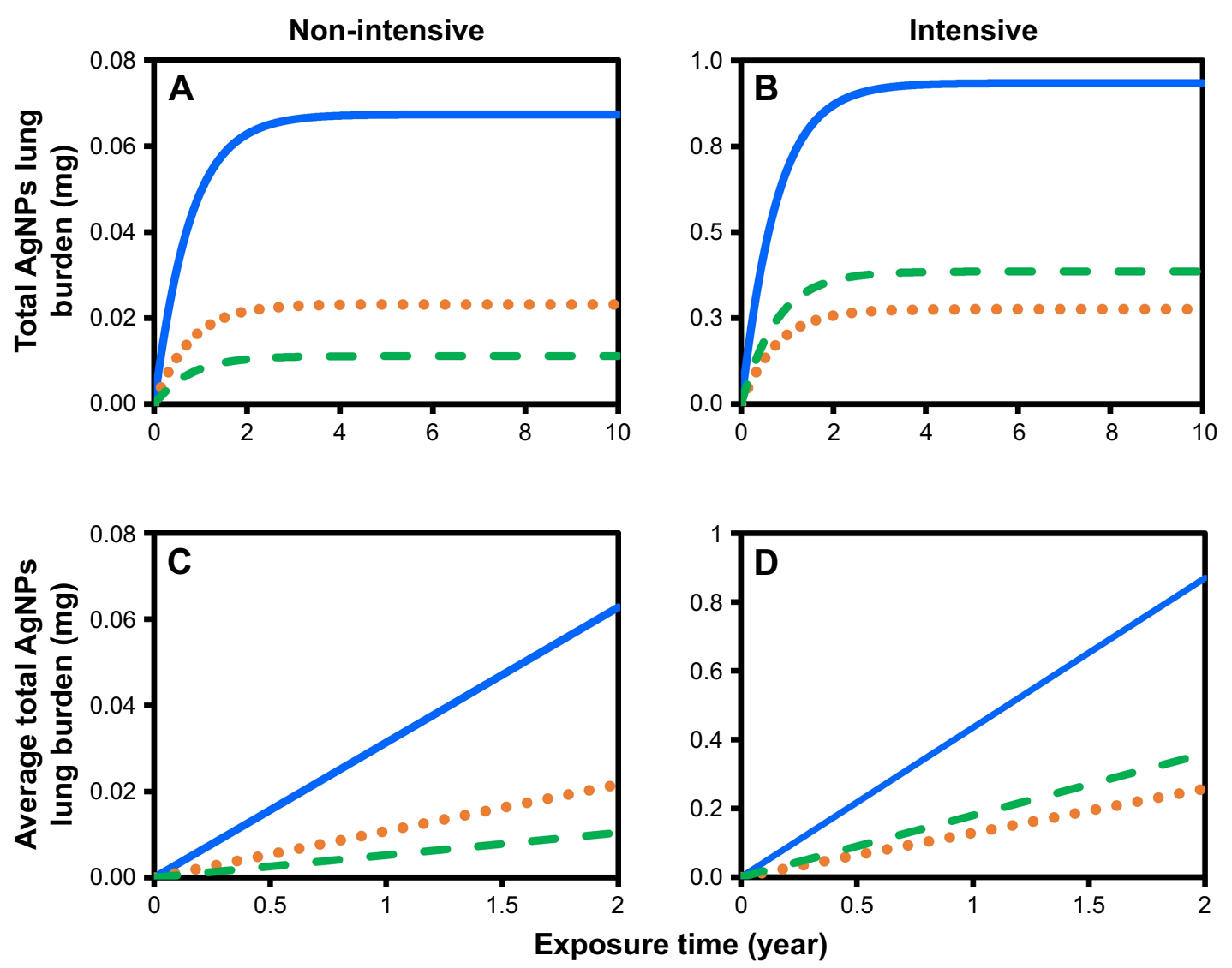

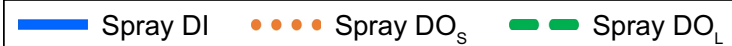

Figure $4(\mathbf{A}, \mathbf{B})$ Total AgNP lung burden and (C, D) accumulation rates after long-term exposure of aerosolized AgNPs released by AgNP-containing spray products in non-intensive and intensive using condition.

Abbreviations: AgNP, silver nanoparticle; $\mathrm{DO}_{S}$, deodorant of $\mathrm{AgNPs}_{\mathrm{s}}$ in smaller scales; $\mathrm{DO}$, deodorant of $\mathrm{AgNPs}$ in larger scales; $\mathrm{DI}$, disinfectant.

in the highest AgNP-induced lung burden $(0.063 \mathrm{mg})$, followed by $\mathrm{DO}_{\mathrm{S}}(0.022 \mathrm{mg})$ and $\mathrm{DO}_{\mathrm{L}}(0.010 \mathrm{mg})$ (Figure $\left.4 \mathrm{~A}\right)$. Within a period of 2 years, the annual accumulation of sprays DI, $\mathrm{DO}_{\mathrm{S}}$, and $\mathrm{DO}_{\mathrm{L}}$ were $0.031,0.011$, and $0.005 \mathrm{mg}$, respectively (Figure 4C).

After 2-year exposure, the intensive application of the sprays DI, $\mathrm{DO}_{\mathrm{S}}$, and $\mathrm{DO}_{\mathrm{L}}$ would result in the following AgNP-induced lung burden: DI (0.870 mg), DO $(0.257 \mathrm{mg})$, and $\mathrm{DO}_{\mathrm{L}}(0.359 \mathrm{mg})$ (Figure $\left.4 \mathrm{~B}\right)$. The annual accumulation of sprays DI, $\mathrm{DO}_{\mathrm{S}}$, and $\mathrm{DO}_{\mathrm{L}}$ were $0.435,0.180$, and $0.132 \mathrm{mg}$, respectively (Figure 4D).

\section{Dose-response analysis}

The Hill-based model provided an effective tool to convert data on AgNP-induced lung burden in humans from published data on rats (as a model organism), based on weight ratio and the effects of inflammation due to an increase in neutrophil expression under exposure to AgNPs of two sizes: $34 \mathrm{~nm}\left(r^{2}=0.79, P<0.001\right)$ and $60 \mathrm{~nm}\left(r^{2}=0.92, P<0.001\right)$
(Figure 5). The quantities of $34 \mathrm{~nm}$ AgNPs required to induce $1 \%, 5 \%, 10 \%$, and $50 \%$ of the maximum increase in neutrophil expression were 1.69, 3.05, 3.98, and $8.73 \mathrm{mg}$, respectively. The quantities of $60 \mathrm{~nm}$ AgNPs required to induce $1 \%, 5 \%, 10 \%$, and $50 \%$ of the maximum increase in neutrophil expression were 5.52, 8.25, 9.89, and $16.88 \mathrm{mg}$, respectively (Table $\mathrm{S} 3$ ). The fitted Hill coefficients $n$ were as follows: $34 \mathrm{~nm}$ NPs (2.80) and $60 \mathrm{~nm}$ NPs (4.11) (Figure 5; Table S3).

\section{Threshold estimation}

The Weibull threshold model provided the best fit to the CDFs of EC1, EC5, and EC10 $\left(r^{2}=0.99, P<0.001\right)$ derived from the profiles indicating the dose-dependent relationship between lung burden and neutrophil expression induced by the inhalation of $34 \mathrm{~nm}$ or $60 \mathrm{~nm}$ AgNPs (Figure S3; Table S4). The fitted threshold estimates (mean $\pm \mathrm{SE}$ ) were as follows: $\gamma_{1}(0.32 \pm 0.22 \mathrm{mg}), \gamma_{5}(0.84 \pm 0.30)$, and $\gamma_{10}(1.26 \pm 0.30$ $\mathrm{mg}$ ) under exposure to $34 \mathrm{~nm}$ AgNPs, and $\gamma_{1}(1.08 \pm 0.64 \mathrm{mg})$, 


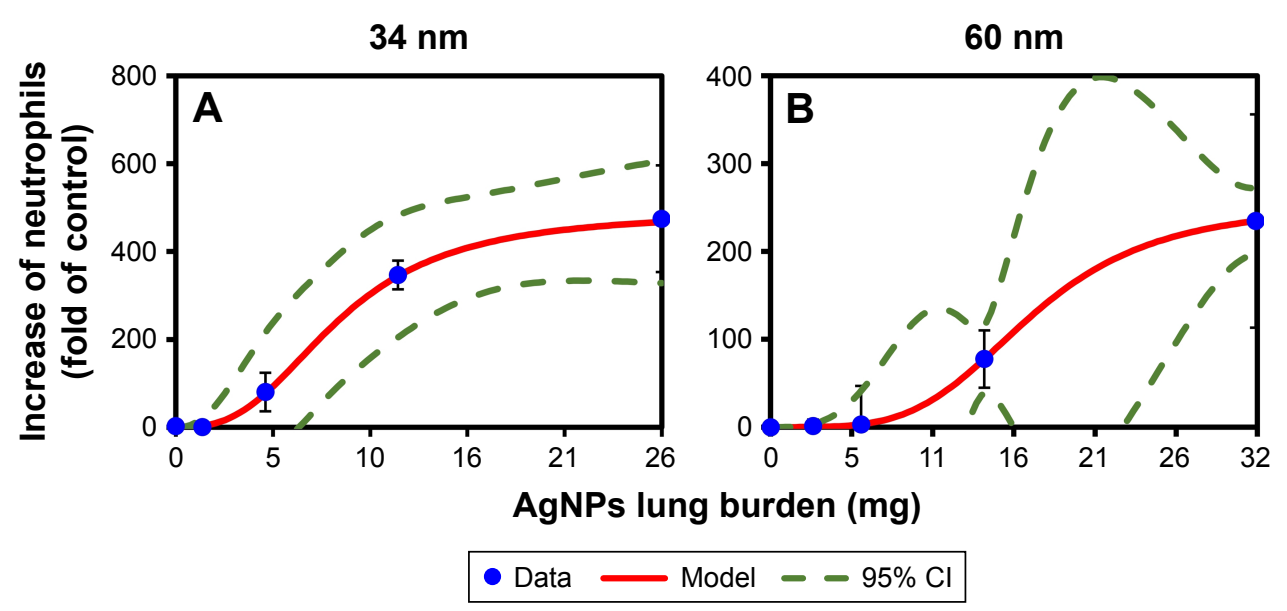

Figure 5 Dose-response describing relationship between lung burdens of (A) $34 \mathrm{~nm}$ and (B) $60 \mathrm{~nm} \mathrm{AgNPs} \mathrm{and} \mathrm{increase} \mathrm{of} \mathrm{neutrophils} \mathrm{in} \mathrm{BALF-based} \mathrm{on} \mathrm{the} \mathrm{Hill} \mathrm{model.}$ Abbreviations: AgNP, silver nanoparticle; BALF, bronchoalveolar lavage fluid.

$\gamma_{5}(1.95 \pm 0.98 \mathrm{mg})$, and $\gamma_{10}(3.23 \pm 0.67 \mathrm{mg})$ under exposure to $60 \mathrm{~nm}$ AgNPs (Figure S3; Table S4).

\section{Risk estimates}

The long-term risks associated with the inhalation of AgNP-containing spray products were characterized under non-intensive and intensive applications using $\gamma_{1}$ as a conservative threshold criterion (Figure 6A and B). Based on the threshold level of $\gamma_{1}$ (exposure to 34 or $60 \mathrm{~nm} \mathrm{AgNPs}$ and the HQ equaling 1), the threshold exposure durations of sprays $\mathrm{DO}_{\mathrm{S}}$ and $\mathrm{DO}_{\mathrm{L}}$ following 2 years of exposure were predicted to be 2.29 hours (95\% CI: $0.83-6.36$ ) and 5.91 hours (95\% CI: 2.21-15.67) per day (Table S5). Overall, the HQs of $\mathrm{DO}_{\mathrm{S}}$ and $\mathrm{DO}_{\mathrm{L}}$ were higher under intensive applications than under non-intensive applications (Figure 6A; Table S5). In non-intensive applications, HQ estimates in all percentiles of $\mathrm{DO}_{\mathrm{S}}$ and $\mathrm{DO}_{\mathrm{L}}$ were $<1$. In intensive applications, HQ estimates in all percentiles were $>1$, as follows: $\mathrm{DO}_{\mathrm{S}}(0.29-3.38)(95 \% \mathrm{CI})$ and $\mathrm{DO}_{\mathrm{L}}(0.14-1.12)$ (Figure 6A; Table S6). There was a probability of 0.495 that HQ estimates of $\mathrm{DO}_{\mathrm{S}}$ exceeded 1 (Figure 6B).

We also estimated the ERs corresponding to specific HQ estimates of $\mathrm{DO}_{\mathrm{S}}$ and $\mathrm{DO}_{\mathrm{L}}$ under non-intensive and intensive applications (Figure 6C-F; Table S7). Overall, the ERs of $\mathrm{DO}_{\mathrm{S}}$ and $\mathrm{DO}_{\mathrm{L}}$ were higher in intensive applications than in non-intensive applications (Figure 6C-F; Table S7). $\mathrm{DO}_{\mathrm{S}}$ presented higher ERs than did $\mathrm{DO}_{\mathrm{L}}$ in nonintensive as well as intensive applications (Figure 6C-F; Table S7). Under 50\% risk probability ( $\mathrm{ER}=0.5)$, the HQ estimates in non-intensive applications were as follows: $\mathrm{DO}_{\mathrm{S}}(0.024-0.284)(95 \% \mathrm{CI})$ and $\mathrm{DO}_{\mathrm{L}}(0.004-0.032)$, and the HQ estimates in non-intensive applications were as follows: $\mathrm{DO}_{\mathrm{S}}(0.288-3.392)(95 \% \mathrm{CI})$ and $\mathrm{DO}_{\mathrm{L}}(0.136-1.123)$ (Figure 6C-F; Table S7).

\section{Sensitivity analysis}

Sensitivity analysis was performed on total AgNP-induced lung burden following 2-year exposure to DI under intensive application. Our objective was to identify the most influential parameters of the PBAD model (Figure 7). The results revealed that except for the phagocytosis rate of macrophage $\left(\mathrm{k}_{\mathrm{p}}\right)$, all of the increments in $\mathrm{k}_{\mathrm{p}}, \mathrm{k}_{\mathrm{c}}, \mathrm{k}_{\mathrm{a}}, \mathrm{k}_{\mathrm{i}}$, and $\mathrm{k}_{\mathrm{l}}$ led to a decrease in AgNP accumulation in the lungs (Figure 7). Moreover, the rate at which AgNPs were transferred from interstitial to lymph node regions $\left(\mathrm{k}_{1}\right)$ was the parameter with the greatest sensitivity to alternations in total AgNP-derived lung burden. This is a clear indication of the high degree to which $\mathrm{k}_{1}$ influences the risks associated with the inhalation of AgN-containing spray products (Figure 7).

\section{Proposed conceptual model}

Our results were used as the basis for the construction of a conceptual model describing the toxicity pathway and mechanisms underlying inflammation resulting from exposure to AgNPcontaining aerosols in conjunction with the PBAD model (Figure 8). As shown in Figure 8, it is possible that AgNPs interact with alveolar epithelial cells through diffusion or endocytosis pathways. Following uptake, AgNPs could translocate to the macrophage region via phagocytosis, followed by the recruitment of neutrophils. Macrophage cells either leave the alveolarmacrophage region in so doing clean out the AgNPs, or undergo apoptosis and in so doing release AgNPs in alveolar regions.

We predict that most of the AgNPs are transferred from alveolar cells into interstitial regions and lymph nodes. When the quantity of accumulated AgNPs exceeds the estimated 

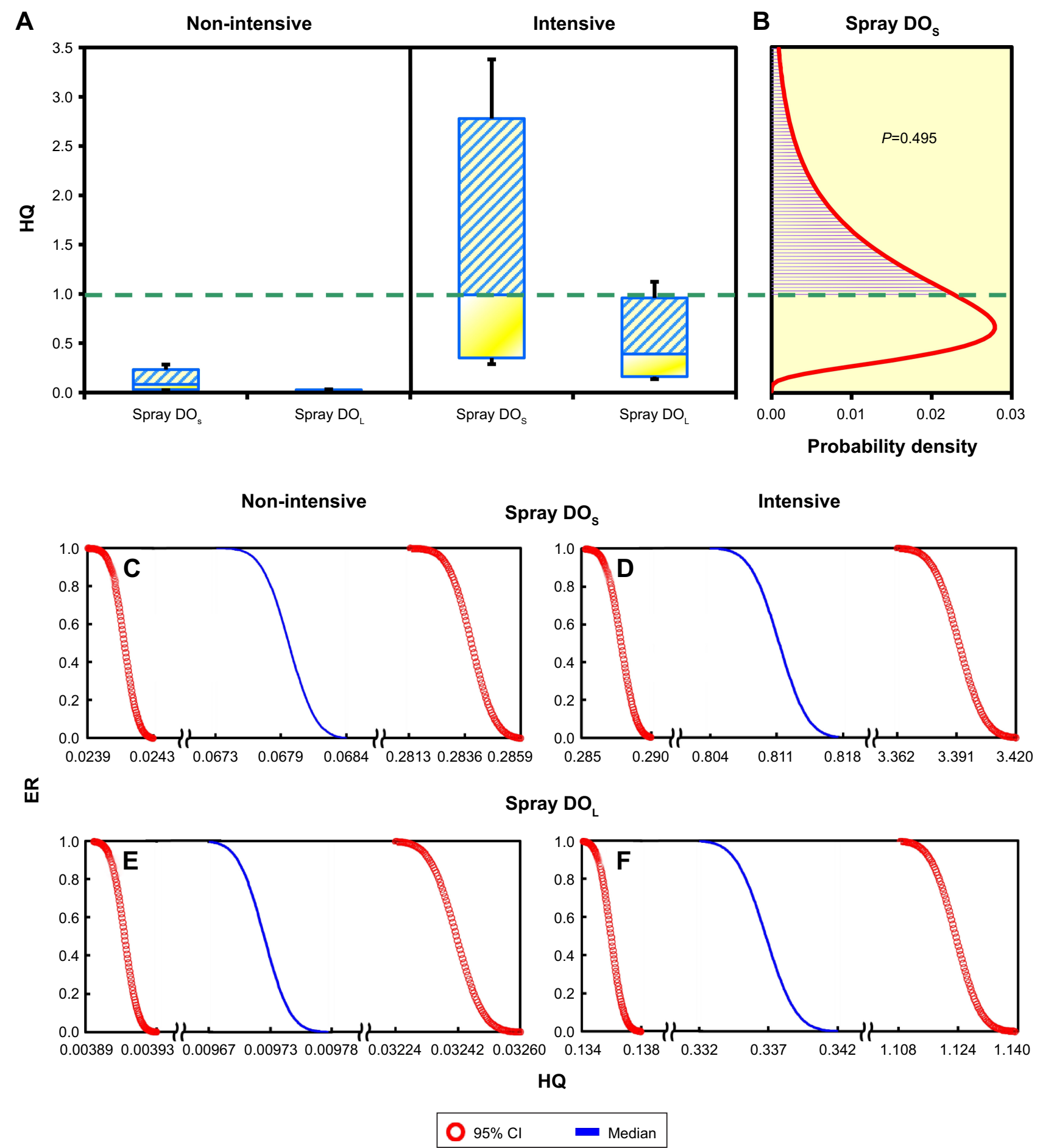

Figure 6 (A) Box and whisker plots of HQs in the criteria of $\gamma_{1}$-based threshold for the elevation of neutrophils in BALF. (B) Probability distribution of HQ exposed to spray $\mathrm{DO}_{s}$ in intensive application, and $\mathrm{ERs}$ for $\mathrm{HQ}$ of using $(\mathbf{C}, \mathbf{D}) \mathrm{DO}_{\mathrm{s}}$ and $(\mathbf{E}, \mathbf{F}) \mathrm{DO}$ in non-intensive or intensive applications.

Abbreviations: $\mathrm{HQ}$, hazard quotients; $\gamma_{1}$, threshold dose preventing from causing $1 \%$ maximum effects on neutrophil elevations; $\mathrm{DO}_{S}$, deodorant of AgNPs in smaller scales; $\mathrm{DO}_{\mathrm{L}}$, deodorant of AgNPs in larger scales; BALF, bronchoalveolar lavage fluid; ER, exceedance risk; AgNP, silver nanoparticle.

threshold level, this can cause mitochondrial dysfunction and ROS generation associated with oxidative stress, followed by the recruitment of inflammation-related cytokines and chemokines leading to macrophage activation. Furthermore, chronic inflammation of the lungs due to the inhalation of AgNPs for prolonged periods could plausibly lead to genotoxicity, the formation of tumor cells, and/or damage to nucleic acids (Figure 8). 


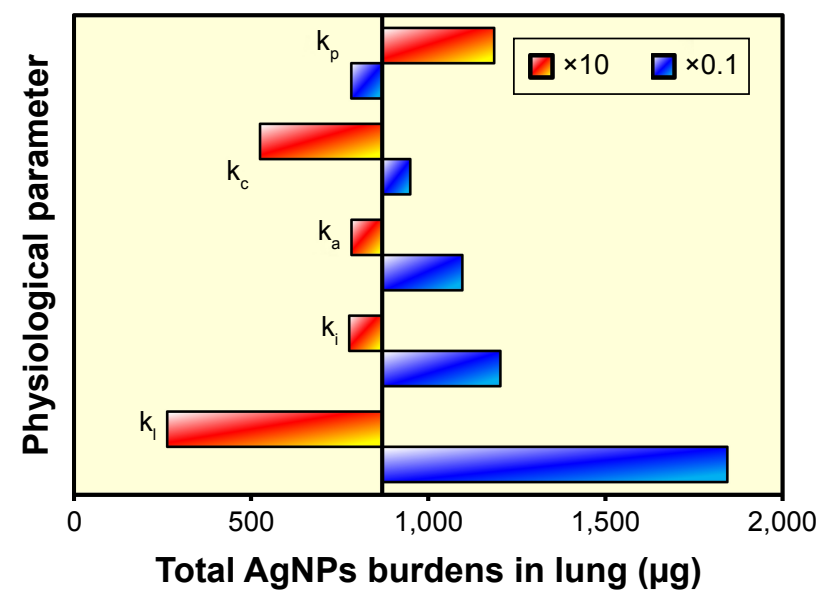

Figure 7 Sensitivity analysis for physiological parameters used in the PBAD model against total AgNP accumulation in human lung $(\mu \mathrm{g})$ posed by aerosolized AgNP spray products.

Abbreviations: AgNP, silver nanoparticle; PBAD, physiologically based alveolar deposition; $k_{i}$, transfer rate of AgNPs from alveolar region to interstitial region; $k_{\text {, }}$ transfer rate of AgNPs from interstitial region to lymph node; $k_{\text {, }}$ phagocytosis rate of macrophage; $k_{a}$, apoptosis rate of macrophage; $k_{c}$, physical clearance rate of nanoparticle.

\section{Discussion}

\section{AgNP spray products: exposure scenarios}

It is crucial that experiments be conducted in scenarios that replicate (as closely as possible) those encountered in the real world. Nonetheless, formulating realistic exposure scenarios involving antibacterial sprays can be hindered by variations in duration, intensity, and frequency of application. ${ }^{25}$

The mass concentrations of the three spray products were measured over a period of 40 minutes ${ }^{15}$ which is close to the values obtained in previous surveys (44.8-143.8 minutes)..$^{20,21}$ The air flow rate in our experiments was $0.0067 \mathrm{~m}^{3} \mathrm{~s}^{-1}$, which is close to the air flow adjacent to desks in an air-conditioned office $\left(0.01-0.047 \mathrm{~m}^{3} \mathrm{~s}^{-1}\right) .{ }^{26}$ This is a clear indication that the duration and flow rate measured in this experiment were representative of real-world scenarios..$^{15}$ Non-intensive applications were simulated by pressing the nozzles of the sprays multiple times, as follows: DI (30 times), $\mathrm{DO}_{\mathrm{S}}$ (10 times), and $\mathrm{DO}_{\mathrm{L}}\left(10\right.$ times). ${ }^{15} \mathrm{We}$ sought to match the daily spray usage behaviors described in previous studies on a household device cleaner, air conditioner deodorizer, and air freshener (5.55 $\left.\mathrm{g} \mathrm{day}^{-1}\right),{ }^{20,21}$ by spraying the samples a set number of times: $\mathrm{DI}(40), \mathrm{DO}_{\mathrm{S}}(4)$, and $\mathrm{DO}_{\mathrm{L}}$ (4). These spray frequencies are close to the experimental settings adopted in a previous study (10-30 times). ${ }^{15}$

The airflow adopted in the experiment was $100 \mathrm{~L} \mathrm{~min}^{-1}$ $\left(24 \mathrm{~m}^{3} \mathrm{~h}^{-1}\right),{ }^{15}$ Sundell et al ${ }^{27}$ claimed that the air exchange rate should exceed $0.5 \mathrm{~h}^{-1}$ to reduce the risk of allergic manifestations among children in a Nordic climate. This translates into air flow of $24 \mathrm{~m}^{3} \mathrm{~h}^{-1}$ for a $48 \mathrm{~m}^{3}$ room to meet the recommended standards. ${ }^{15,28}$ It has been estimated that the average short-term air exchange rate in the US is $0.65 \mathrm{~h}^{-1}$, reaching $2-3 \mathrm{~h}^{-1}$ in rooms with open windows. This means that in several realistic scenarios, the AgNP concentrations from AgNP-containing sprays could be below the measurements reported by $\mathrm{Hsu},{ }^{15}$ particularly in cases of higher air exchange rates $\left(>0.5 \mathrm{~h}^{-1}\right){ }^{28}$

\section{Modeling of aerosol deposition in alveolar region}

The alveolar deposition (PBAD) model when implemented within a risk assessment framework proved highly effective in predicting the total and regional lung burden of AgNPs from aerosol emissions. For decades, researchers have been developing models to describe the deposition of airborne toxicants in the respiratory system. Mathematical modeling can be used to overcome the limitations of in vitro and in vivo models in assessing dynamic and long-term aerosol deposition. This approach examines particle deposition and clearance from a mechanistic viewpoint. In the biomathematical model developed by Kuempel et al, ${ }^{16,17}$ the kinetic processes of airborne particles are first formulated within the context of compartments (alveolar, interstitial, and hilar lymph nodes). That three-compartment model proved highly effective in predicting the long-term dust-derived lung burden among coal miners as well as the distribution of inhaled silica in specific lung regions. ${ }^{16-19}$

Computational fluid dynamics and multiple path particle deposition models have also been used to estimate the deposition of diesel exhaust particles, hygroscopic particulate matters, and other ultrafine aerosols in human lungs. ${ }^{29-31}$ Lung models with various compartments have also been constructed to obtain estimates of NP burdens in the human respiratory tract. ${ }^{32-34}$ The International Commission on Radiological Protection revised the respiratory tract dosimetry model as a five-compartment model by including the alveolar-interstitial region. ${ }^{35,36}$

In another study, a physiological lung model was used to predict the burden associated with titanium dioxide NPs in alveolar surface areas among workers in the manufacturing industry. ${ }^{37}$ Liao et al ${ }^{38}$ used the PBAD model to assess the silica threshold levels among workers facing long-term exposures in ceramic manufacturing facilities.

\section{Toxicity of inhaled AgNP-containing aerosols}

It has been widely reported that inhalable NPs penetrate the lung alveoli more deeply than larger particles. The alveoli 


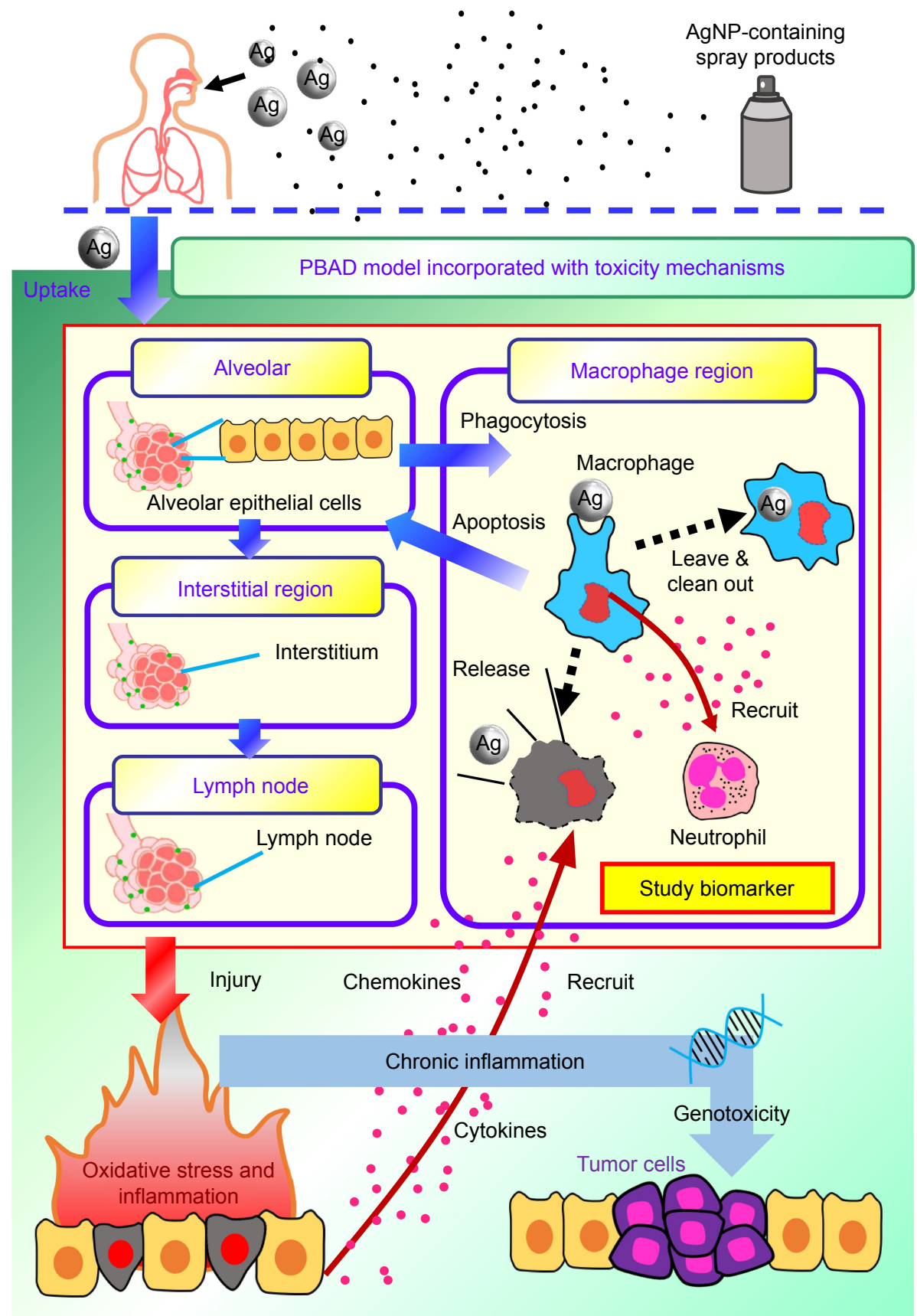

Figure 8 A conceptual model showing mechanisms of inflammation response exposed to aerosolized AgNPs via inhalation. Abbreviations: AgNP, silver nanoparticle; PBAD, physiologically based alveolar deposition.

consists only of surfactant with a small number of cells separating the gaseous phase from the blood. In this environment, it is very easy for inhaled NPs to be transported into the bloodstream. ${ }^{39-41}$ Takenaka et $\mathrm{al}^{42}$ reported on the translocation of AgNPs $(14.6 \pm 1.0 \mathrm{~nm})$ from the lungs into the heart, liver, kidney, and brain in rats following exposure via inhalation and instillation. Kwon et $\mathrm{al}^{43}$ measured $\mathrm{Ag}$ distributions in various organs in mice. They also observed mild pulmonary toxicity associated with the activation of mitogen-activated protein kinase signaling.
Numerous researchers have investigated the biological effects of inhaled AgNP-containing aerosols in murine systems. Under acute exposure scenarios, Sung et $\mathrm{a}^{44}$ observed no significant difference in terms of body weight or lung function in Sprague Dawley rats exposed to aerosolized AgNPs (average diameter of $18-20 \mathrm{~nm}$ at concentration reaching $750 \mathrm{mg} \mathrm{m}^{-3}$ ) over an observation period of 2 weeks. Roberts et $\mathrm{al}^{45}$ also reported that the short-term inhalation of $100 \mu \mathrm{g} \mathrm{m}^{-3} \mathrm{AgNPs}$ in commercial antimicrobial products had no acute toxic effects in Sprague Dawley rats. 
However, other studies on acute exposure reported several biological responses at specific endpoints or at the molecular level. Hyun et $\mathrm{al}^{5}$ reported increases in the size and number of goblet cells containing neutral mucins in Sprague Dawley rat lungs exposed to aerosolized AgNPs for a period of 28 days. Campagnolo et $\mathrm{al}^{46}$ detected AgNPs in maternal tissues, placentas, and fetuses of pregnant mice after exposure to $640 \mathrm{\mu g} \mathrm{m}^{-3}$ aerosolized AgNPs for 15 days. They also reported an increase in cytokine-related inflammation. Lee et $\mathrm{al}^{47}$ observed gene expression in brains associated with neurodegenerative diseases, motor neuron disorders, and immune cell functions following sub-chronic exposure to $22 \mathrm{~nm}$ AgNPs via inhalation over a period of 14 days.

Under subchronic exposure scenarios, researchers have reported a decrease in lung tidal volume as well as inflammation of the alveolar and liver and abnormal bile duct hyperplasia in Sprague Dawley rats exposed to airborne AgNPs for 90 days. ${ }^{5,6,48}$ Clearly, the effects of long-term exposure to airborne AgNPs cannot be disregarded. Further research on the risks of inhalation using long-term experimental data is required.

The physiochemical properties of NPs, such as particle size and surface characteristics, also play a vital role on respiratory toxicity. Braakhuis et $\mathrm{al}^{49}$ investigated the sizedependent effects of AgNPs of different sizes but similar mass concentrations in a short-term inhalation experiment. They found that $15 \mathrm{~nm}$ AgNPs had moderate pulmonary effects on Fischer rats, whereas the $410 \mathrm{~nm}$ particles had no observable effects at all. In another study, it was shown that $20 \mathrm{~nm}$ AgNPs had a more pronounced effect on inflammation via intratracheal installation compared to $110 \mathrm{~nm} \mathrm{AgNPs,} \mathrm{as}$ evidenced by neutrophil influx. ${ }^{7}$

\section{Mechanisms underlying AgNP-induced inflammation in human lungs}

Previous in vivo and in vitro studies have also noted the importance of ROS in dictating toxic responses to AgNPs. McShan et $\mathrm{al}^{50}$ and Cheng et $\mathrm{al}^{51}$ suggested that in mammalian cells, AgNPs disrupt fibroblast membranes, thereby allowing the influx of calcium, which leads to intracellular calcium overload and the subsequent overproduction of ROS. Kruszewski et $\mathrm{al}^{52}$ observed the production of ROS in human lung carcinoma (A549) exposed to AgNPs (20 or $200 \mathrm{~nm}$ ) at concentrations of 10,50 , or $100 \mathrm{mg} \mathrm{mL}^{-1}$ over periods of 2-24 hours.

In concert with the proposed inflammation pathway, Braakhuis et $\mathrm{al}^{24}$ reported an increase in pro-inflammatory cytokines, interleukin-1 $\beta$ (IL-1 $\beta$ ), tumor necrosis factor- $\alpha$, monocyte chemoattractant protein (MCP-1), and regulated on activation, normal T cell expressed and secreted (RANTES) in the bronchoalveolar lavage fluid (BALF) of Fischer rats exposed to $40-1,100 \mu \mathrm{g} \mathrm{m}^{-3}$ AgNPs via inhalation over a period of 4 days. Several studies also demonstrated that ROS production exceeding the neutralizing capacity of antioxidants leads to the activation of inflammatory responses, such as IKK/NF-kB pathways and the release of chemokines or cytokines (eg, IL-1 $\beta$ ) aimed at recruiting inflammatory cells (eg, neutrophils and macrophages) to remove invasive NPs. ${ }^{53-55}$

Numerous studies have investigated genotoxicity or DNA damage associated with oxidative stress following exposure to AgNPs. AshaRani et $\mathrm{al}^{56}$ suggested that a disruption of the mitochondrial respiratory chain by AgNPs could increase ROS production, interrupt ATP synthesis, and cause DNA damage. Hackenberg et $\mathrm{al}^{57}$ reported that AgNPs induce genotoxic effects in human mesenchymal stem cells. Strong proinflammatory responses and DNA damage have also been observed in transformed human alveolar epithelial type-1like cells. ${ }^{58}$ Several studies have linked comet tail length and apoptosis in cell cultures to DNA damage. ${ }^{59,60}$ Nallanthighal et $\mathrm{al}^{61}$ reported that humans with genetic polymorphisms are more susceptibile to AgNP-mediated DNA damage.

There is a growing body of evidence suggesting that NPs-exposed inflammatory cells (eg, neutrophils and macrophages) induce inflammation through ROS production and generated oxidative DNA damage. ${ }^{50,51,62-64}$ Rahban et al ${ }^{65}$ reported that AgNPs affect calf thymus, resulting in DNA that is tightly bound with altered conformation. AshaRani et al ${ }^{66}$ reported corona induction and DNA damage-related gene expressions in cytosolic proteins. They also found evidence of DNA double-strand breakage manifesting as an increase in ataxia telangiectasia mutated (ATM) and ATM-related levels in normal lung fibroblast cells (U251). ${ }^{66}$

\section{Administrative strategies to reduce the risk of long-term inhalation}

There are at present no regulations pertaining to airborne/aerosolized AgNPs in commercial spray products. The permissible exposure limit established by the OSHA for airborne Ag particles (metallic or soluble forms) is $0.01 \mathrm{mg} \mathrm{m}^{-3} .{ }^{67}$ The American Conference of Governmental Industrial Hygienists (ACGIH) also established the threshold limit of $0.1 \mathrm{mg} \mathrm{m}^{-3}$ for metallic Ag dust. ${ }^{68}$ However, it should be noted that the toxic effects of airborne AgNPs differ fundamentally from that of other $\mathrm{Ag}$ compounds due to differences in particle size and chemical forms makeup. It is very likely that standards will have to be established specifically for AgNP-containing spray products.

Sung et $\mathrm{al}^{48}$ reported that the threshold level of no observable chronic alveolar inflammation was $0.1 \mathrm{mg} \mathrm{m}^{-3}$ 
in Sprague Dawley rats following the inhalation of AgNPs of $\sim 20 \mathrm{~nm}$. This is consistent with the threshold limit established by the ACGIH. ${ }^{68}$ However, it should be noted that the threshold level is based on a no-observed-adverse-effectlevel in a murine system that underwent sub-chronic exposure for a period of 13 weeks. In this study, we sought to establish a representative threshold value for human lungs exposed to AgNPs under long-term exposure scenarios by formulating a risk assessment scheme that incorporates tools for extrapolation (from rats to human) with mathematical modeling.

Protective measures have been established for workers in several fields; however, the development of strategies for the prevention of AgNP exposure is lagging. The International Organization for Standardization (ISO) has introduced the control banding approach to limit exposure to NPs, such as Ag oxides from fume hoods and local exhaust ventilation for engineered nanomaterials. ${ }^{69,70}$ Respiratory protection devices, such as respirators, have also been certified by the NIOSH for various occupations in the US. ${ }^{71}$ However, none of these measures address the issue of exposures to NPs by consumers. Further regulations pertaining to the management of AgNP aerosols released from commercial spray products should be strengthened for the protection of consumers.

The European Commission and ISO are currently regulating the labeling of nano-objects in cosmetics and other consumer products. ${ }^{72-74}$ However, the standards used in the labeling of NPs in spray products remains unclear. Regulations pertaining to AgNP content in commercial spray products are of paramount concern, due to the direct exposure to pulmonary regions and potential risks associated with human inhalation over extended periods.

Adopting the threshold exposure durations of each product would be a more practical approach to reducing the risks of inhalation. Park et $\mathrm{al}^{20}$ reported that using sprays in wellventilated areas and remaining at a distance from the spray source after spraying could reduce the amount of particles that are inhaled. Thus, the predicted threshold exposure durations were 2.29 hours per day for $\mathrm{DO}_{\mathrm{S}}$ and 5.91 hours per day for $\mathrm{DO}_{\mathrm{L}}$, in accordance with the requirement the usage of these sprays does not result in a HQ exceeding 1 within a period of 2 years.

The risks associated with inhaling the two spray products in this study could be mediated by labeling the spray products with a recommended threshold exposure duration. Workers, such as cleaners, should definitely wear respirators or use ventilation systems when using these or similar products. ${ }^{75}$

The type of nozzle also plays an important role in persistence and the dispersion distance of aerosols. We found that the long-term use of propellant-type bottles leads to a higher mass concentrations of AgNPs in the lungs, compared to the use of pump-type spray bottles. Pump sprays generate larger droplets, which settle more rapidly. It is reasonable therefore to surmise that the application of pump nozzles in spray products could reduce the resulting lung burden of toxicants in the human body. ${ }^{20}$

Control equipment with high NP-collection efficiency could also be used to reduce the volume of aerosolized AgNPs in the ambient environment during the production of AgNPs. ${ }^{1}$ It is also necessary to enforce risk assessments when dealing with other manufactured NPs that are frequently added to commercial spray products (eg, titanium dioxide, copper oxide, and siloxane-modified alumina).${ }^{76}$ Our proposed risk assessment framework in conjunction with the PBAD model could be applied to assess the hazards imposed by any NPs on the human respiratory system.

\section{Limitations and implications}

In this study, we assessed the risks posed by exposure to AgNP-containing spray products using a well-established risk assessment scheme in conjunction with mathematical modeling and experimental data. However, it should be noted that the exposure scenarios in laboratory experiments (ie, NPs of homogeneous purity and purified air streams) do not necessarily reflect the conditions encountered in the real-world. ${ }^{77}$ Even minor factors such as spatial-temporal dispersion (applied distance, frequency of use), nozzle and solvent types, indoor ventilation, and air flow rate could lead to considerable variation in the concentrations of AgNPs inhaled from aerosols. ${ }^{20,78}$

The agglomeration and aggregation of NPs in the presence of water and organic solvents in consumer spray products could affect the morphology, size distribution, and surface area of NPs. ${ }^{18}$ EDX technology can be incorporated with TEM analysis to identify the elements in NPs in aerosols from spray products. EDX could be also used to explore bioaccumulations and distributions of AgNPs in human lungs. Finally, EDX could be implemented in conjunction with a mechanistic in cases where specimens of BALF are available. $^{79,80}$

Most of the NP-containing aerosol particles enter the human respiratory tract; however, Bressan et $\mathrm{al}^{62}$ reported the accumulation of AgNPs outside mitochondria in human dermal fibroblasts, suggesting the potential toxicity of AgNPs via the dermal route. ${ }^{81}$ Further research will be required to verify those findings and explore the implications for human health. 


\section{Conclusion}

This paper presents a novel approach to risk assessment based on mechanistic modeling (using empirical nanotoxicity data obtained in a rat model) to estimate the risks associated with the chronic inhalation of AgNPs from spray products. The PBAD model-based risk assessment framework is meant to overcome the limitations of assessing risks of spray products over extended time scales in an experimental setting. This powerful tool can be used to derive the long-term AgNP-derived lung burden and obtain risk estimates of NPcontaining aerosols. The proposed risk assessment scheme provides considerable insight into the relationship between the characteristics of metallic NP-containing spray products and the corresponding toxicities over various time scales.

\section{Acknowledgment}

This study was supported by the Ministry of Science and Technology of Republic of China under grant MOST 105-2313-B-002-020-MY3.

\section{Author contributions}

All authors contributed to data analysis, drafting and revising the article, gave final approval of the version to be published, and agree to be accountable for all aspects of the work.

\section{Disclosure}

The authors report no conflicts of interest in this work.

\section{References}

1. Quadros ME, Marr LC. Environmental and human health risks of aerosolized silver nanoparticles. J Air Waste Manag Assoc. 2010;60(7):770-781.

2. Galandáková A, Franková J, Ambrožová N, et al. Effects of silver nanoparticles on human dermal fibroblasts and epidermal keratinocytes. Hum Exp Toxicol. 2016;35(9):946-957.

3. Hagendorfer H, Lorenz C, Kaegi R, et al. Size-fractionated characterization and quantification of nanoparticle release rates from a consumer spray product containing engineered nanoparticles. $J$ Nanopart Res. 2010;12(7):2481-2494.

4. Foldbjerg R, Dang DA, Autrup H. Cytotoxicity and genotoxicity of silver nanoparticles in the human lung cancer cell line, A549. Arch Toxicol. 2011;85(7):743-750.

5. Hyun J-S, Lee BS, Ryu HY, et al. Effects of repeated silver nanoparticles exposure on the histological structure and mucins of nasal respiratory mucosa in rats. Toxicol Lett. 2008;182(1-3):24-28.

6. Sung JH, Ji JH, Yoon JU, et al. Lung function changes in Sprague-Dawley rats after prolonged inhalation exposure to silver nanoparticles. Inhal Toxicol. 2008;20(6):567-574.

7. Seiffert J, Hussain F, Wiegman C, et al. Pulmonary toxicity of instilled silver nanoparticles: influence of size, coating and rat strain. PLoS One. 2015;10(3): 0119726.

8. Stebounova LV, Adamcakova-Dodd A, Kim JS, et al. Nanosilver induces minimal lung toxicity or inflammation in a subacute murine inhalation model. Part Fibre Toxicol. 2011;8(1):5.

9. Wijnhoven SWP, Peijnenburg WJGM, Herberts CA, et al. Nano-silver-a review of available data and knowledge gaps in human and environmental risk assessment. Nanotoxicology. 2009;3(2):109-138.
10. Losert S, von Goetz N, Bekker C, et al. Human exposure to conventional and nanoparticle - containing sprays - a critical review. Environ Sci Technol. 2014;48(10):5366-5378.

11. Occupational safety and Health Administration (OSHA) Chemical Sampling Information. Silver, Metal \& Soluble Compounds (as Ag). Washington, DC: U.S. Department of Labor; 2005.

12. NIOSH. Pocket Guide to Chemical Hazards. Atlanta, GA, United States of America: NIOSH, National Institute for Occupational Safety and Health Publication, U.S. Centers for Disease Control and Prevention; 2005:1492005.

13. USEPA. Federal insecticide, fungicide, and rodenticide Act (FIFRA) and federal facilities; 2018. Available from: https://www.epa.gov/ enforcement/federal-insecticide-fungicide-and-rodenticide-act-fifraand-federal-facilities. Accessed September 02, 2018.

14. EU. Regulation (EU) NO 528/2012 of the European Parliament and of the Council of 22 May 2012 concerning the making available on the market and use of biocidal products text with EEA relevance; 2012. Available from: https://eur-lex.europa.eu/legal-content/EN/TXT/PDF/? uri=CELEX:32012R0528\&from=EN. Accessed September 02, 2018.

15. Hsu YR. Characterization of Nanoparticles Released from Commercial Nanosilver-Containing Spray Products [MS thesis]. Hsinchu, Taiwan ROC: National Chiao Tung University; 2016.

16. Kuempel ED, O'Flaherty EJ, Stayner LT, et al. A biomathematical model of particle clearance and retention in the lungs of coal miners. Regul Toxicol Pharmacol. 2001;34(1):69-87.

17. Kuempel ED, Tran CL, Smith RJ, Bailer AJ. A biomathematical model of particle clearance and retention in the lungs of coal miners. II. Evaluation of variability and uncertainty. Regul Toxicol Pharmacol. 2001; 34(1):88-101.

18. Tran CL, Graham M, Buchanan D. A Biomathematical Model for Rodent and Human Lung Describing Exposure, Dose, and Response to Inhaled Silica. Edinburgh, UK: Institute of Occupational Medicine; 2001.

19. Kuempel ED, Castranova V, Tran CL. A rat lung model of exposure, dose and response to inhaled silica. Ann Occup Hyg. 2002;46(Suppl 1): $14-17$.

20. Park J, Ham S, Jang M, et al. Spatial-temporal dispersion of aerosolized nanoparticles during the use of consumer spray products and estimates of inhalation exposure. Environ Sci Technol. 2017;51(13):7624-7638.

21. KMOE. Notification No. 2014-50 of the National Institute of Environmental Research: Regulation on objects and method of product risk assessment. KMOE, Korean Ministry of Environment, Sejong Special Autonomous City, Republic of Korea 2014.

22. MOHW. DOH96-HP-1801: Compilation of Exposure Factors. Taipei, Republic of China: Ministry of Health and Welfare; 2007.

23. Bourne DW. Mathematical Modeling of Pharmacokinetic Data. Chicago: Technomic; 1995.

24. Braakhuis HM, Cassee FR, Fokkens PHB, et al. Identification of the appropriate dose metric for pulmonary inflammation of silver nanoparticles in an inhalation toxicity study. Nanotoxicology. 2016;10(1): 63-73.

25. Kim E, Lee JH, Kim JK, et al. Case study on risk evaluation of silver nanoparticle exposure from antibacterial sprays containing silver nanoparticles. J Nanomater. 2015;2015:8.

26. Loomans M. The Measurement and Simulation of Indoor Air Flow. Eindhoven: University of Eindhoven; 1998.

27. Sundell J, Levin H, Nazaroff WW, et al. Ventilation rates and health: multidisciplinary review of the scientific literature. Indoor Air. 2011; 21(3):191-204.

28. Wallace LA, Emmerich SJ, Howard-Reed C. Continuous measurements of air change rates in an occupied house for 1 year: the effect of temperature, wind, fans and windows. J Expo Sci Environ Epidemiol. 2002;12(4): 296-306.

29. Alföldy B, Giechaskiel B, Hofmann W, Drossinos Y. Size-distribution dependent lung deposition of diesel exhaust particles. J Aerosol Sci. 2009;40(8):652-663.

30. Asgharian B. A model of deposition of hygroscopic particles in the human lung. Aerosol Sci Technol. 2004;38(9):938-947. 
31. Rostami AA. Computational modeling of aerosol deposition in respiratory tract: a review. Inhal Toxicol. 2009;21(4):262-290.

32. Kuempel ED, Tran CL, Castranova V, Bailer AJ. Lung dosimetry and risk assessment of nanoparticles: evaluating and extending current models in rats and humans. Inhal Toxicol. 2006;18(10):717-724.

33. Maccalman L, Tran CL, Kuempel E. Development of a bio-mathematical model in rats to describe clearance, retention and translocation of inhaled nano particles throughout the body. J Phys Conf Ser. 2009; 151(1):012028.

34. Shinohara N, Oshima Y, Kobayashi T, et al. Dose-dependent clearance kinetics of intratracheally administered titanium dioxide nanoparticles in rat lung. Toxicology. 2014;325:1-11.

35. Bevelacqua JJ. Health Physics: Radiation-Generating Devices, Characteristics, and Hazards. Hoboken, NJ: John Wiley \& Sons; 2016.

36. ICRP. Human respiratory tract model for radiological protection, a report of a task group of the International Commission on radiological protection. Ann ICRP. 1994;24(1-3):1-482.

37. Liao C-M, Chiang Y-H, Chio C-P. Model-based assessment for human inhalation exposure risk to airborne nano/fine titanium dioxide particles. Sci Total Environ. 2008;407(1):165-177.

38. Liao C-M, Wu B-C, Cheng Y-H, et al. Ceramics manufacturing contributes to ambient silica air pollution and burden of lung disease. Environ Sci Pollut Res. 2015;22(19):15067-15079.

39. Balasubramanian SK, Poh K-W, Ong C-N, et al. The effect of primary particle size on biodistribution of inhaled gold nano-agglomerates. Biomaterials. 2013;34(22):5439-5452.

40. Kendall M, Holgate S. Health impact and toxicological effects of nanomaterials in the lung. Respirology. 2012;17(5):743-758.

41. Kreyling WG, Hirn S, Möller W, et al. Air-blood barrier translocation of tracheally instilled gold nanoparticles inversely depends on particle size. ACS Nano. 2014;8(1):222-233.

42. Takenaka S, Karg E, Roth C, et al. Pulmonary and systemic distribution of inhaled ultrafine silver particles in rats. Environ Health Perspect. 2001;109 (Suppl 4):547.

43. Kwon J-T, Minai-Tehrani A, Hwang S-K, et al. Acute pulmonary toxicity and body distribution of inhaled metallic silver nanoparticles. Toxicol Res. 2012;28(1):25-31.

44. Sung JH, Ji JH, Song KS, et al. Acute inhalation toxicity of silver nanoparticles. Toxicol Ind Health. 2011;27(2):149-154.

45. Roberts JR, Mckinney W, Kan H, et al. Pulmonary and cardiovascular responses of rats to inhalation of silver nanoparticles. J Toxicol Environ Health A. 2013;76(11):651-668.

46. Campagnolo L, Massimiani M, Vecchione L, et al. Silver nanoparticles inhaled during pregnancy reach and affect the placenta and the foetus. Nanotoxicology. 2017;11(5):687-698.

47. Lee H-Y, Choi Y-J, Jung E-J, et al. Genomics-based screening of differentially expressed genes in the brains of mice exposed to silver nanoparticles via inhalation. J Nanopart Res. 2010;12(5):1567-1578.

48. Sung JH, Ji JH, Park JD, et al. Subchronic inhalation toxicity of silver nanoparticles. Toxicol Sci. 2009;108(2):452-461.

49. Braakhuis HM, Gosens I, Krystek P, et al. Particle size dependent deposition and pulmonary inflammation after short-term inhalation of silver nanoparticles. Part Fibre Toxicol. 2014;11(1):49.

50. Mcshan D, Ray PC, Yu H. Molecular toxicity mechanism of nanosilver. J Food Drug Anal. 2014;22(1):116-127.

51. Cheng X, Zhang W, Ji Y, et al. Revealing silver cytotoxicity using Au nanorods/Ag shell nanostructures: disrupting cell membrane and causing apoptosis through oxidative damage. RSC Adv. 2013;3(7):2296-2305.

52. Kruszewski M, Grądzka I, Bartłomiejczyk T, et al. Oxidative DNA damage corresponds to the long term survival of human cells treated with silver nanoparticles. Toxicol Lett. 2013;219(2):151-159.

53. Shi J, Sun X, Lin Y, et al. Endothelial cell injury and dysfunction induced by silver nanoparticles through oxidative stress via IKK/NF- $\mathrm{\kappa B}$ pathways. Biomaterials. 2014;35(24):6657-6666.

54. Wang Z, Xia T, Liu S. Mechanisms of nanosilver-induced toxicological effects: more attention should be paid to its sublethal effects. Nanoscale. 2015;7(17):7470-7481.
55. Yang E-J, Kim S, Kim JS, Choi I-H. Inflammasome formation and IL-1 $\beta$ release by human blood monocytes in response to silver nanoparticles. Biomaterials. 2012;33(28):6858-6867.

56. Asharani PV, Low Kah Mun G, Hande MP, Valiyaveettil S. Cytotoxicity and genotoxicity of silver nanoparticles in human cells. ACS Nano. 2009;3(2):279-290.

57. Hackenberg S, Scherzed A, Kessler M, et al. Silver nanoparticles: evaluation of DNA damage, toxicity and functional impairment in human mesenchymal stem cells. Toxicol Lett. 2011;201(1):27-33.

58. Zambianchi MZ, Tetley TD, Thorley AJ. S97 Alveolar epithelial DNA damage, inflammation and altered autophagy following exposure to silver nanoparticles is exacerbated by viral ligands in vitro. Thorax. 2013;68(Suppl 3):A52.

59. Awasthi KK, Awasthi A, Kumar N, et al. Silver nanoparticle induced cytotoxicity, oxidative stress, and DNA damage in CHO cells. J Nanopart Res. 2013;15(9):1898.

60. Awasthi KK, Awasthi A, Verma R, et al. Silver nanoparticles and carbon nanotubes induced DNA damage in mice evaluated by single cell gel electrophoresis. Macromol Symp. 2015;357(1):210-217.

61. Nallanthighal S, Chan C, Murray TM, et al. Differential effects of silver nanoparticles on DNA damage and DNA repair gene expression in Ogg1deficient and wild type mice. Nanotoxicology. 2017;11(8):996-1011.

62. Bressan E, Ferroni L, Gardin C, et al. Silver nanoparticles and mitochondrial interaction. Int J Dent. 2013;2013:1-8.

63. He D, Jones AM, Garg S, Pham AN, Waite TD. Silver nanoparticlereactive oxygen species interactions: application of a chargingdischarging model. J Phys Chem C. 2011;115(13):5461-5468.

64. Schins RPF, Knaapen AM. Genotoxicity of poorly soluble particles. Inhal Toxicol. 2007;19(sup1):189-198.

65. Rahban M, Divsalar A, Saboury AA, Golestani A. Nanotoxicity and spectroscopy studies of silver nanoparticle: Calf thymus DNA and K562 as targets. J Phys Chem C. 2010;114(13):5798-5803.

66. Asharani PV, Sethu S, Lim H, et al. Differential regulation of intracellular factors mediating cell cycle, DNA repair and inflammation following exposure to silver nanoparticles in human cells. Genome Integr. 2012;3(1):2.

67. Osha.gov. OSHA annotated table Z-1. Available from: https://www. osha.gov/dsg/annotated-pels/tablez-1.html. Accessed September 1, 2018.

68. ACGIH. Documentation of the Threshold Limit Values and Biological Exposure Indices. Cincinnati, OH: ACGIH, American Conference of Governmental Industrial Hygienists; 2007.

69. ISO. ISO/TS 12901-2: Nanotechnologies-Occupational Risk Management Applied to Engineered Nanomaterial-Part 2: Use of the Control Banding Approach. Geneva, Switzerland: ISO, The International Organization for Standardization; 2014

70. Zalk DM, Paik SY, Swuste P. Evaluating the control banding nanotool: a qualitative risk assessment method for controlling nanoparticle exposures. J Nanopart Res. 2009;11(7):1685-1704.

71. OSHA. Fed Regist 63:1152-1300: Respiratory Protection. Washington, DC: Occupational Safety and Health Administration (OSHA); 1998.

72. Gruère GP. Labeling nano-enabled consumer products. Nano Today. 2011;6(2):117-121.

73. Rauscher H, Rasmussen K, Sokull-klüttgen B. Regulatory aspects of nanomaterials in the EU. Chem Ing Tech. 2017;89(3):224-231.

74. ISO. ISO/TS 13830: Nanotechnologies-Guidance on Voluntary Labelling for Consumer Products Containing Manufactured Nano-Objects. Geneva, Switzerland: The International Organization for Standardization (ISO); 2013.

75. EHS. EHS-DOC-035: Nanomaterials Safety Guidelines, Version 4. Montreal, Canada: Concordia University Environmental Health and Safety (EHS); 2017.

76. Shaffer RE, Rengasamy S. Respiratory protection against airborne nanoparticles: a review. J Nanopart Res. 2009;11(7):1661-1672.

77. Quadros ME, Marr LC. Silver nanoparticles and total aerosols emitted by nanotechnology-related consumer spray products. Environ Sci Technol. 2011;45(24):10713-10719. 
78. Bekker C, Brouwer DH, van Duuren-Stuurman B, et al. Airborne manufactured nano-objects released from commercially available spray products: temporal and spatial influences. J Expo Sci Environ Epidemiol. 2014;24(1):74-81.

79. Scimeca M, Bischetti S, Lamsira HK, Bonfiglio R, Bonanno E. Energy dispersive X-ray (EDX) microanalysis: a powerful tool in biomedical research and diagnosis. Eur J Histochem. 2018;62(1):2841.
80. Scimeca M, Pietroiusti A, Milano F, et al. Elemental analysis of histological specimens: a method to unmask nano asbestos fibers. Eur $J$ Histochem. 2016;60(1):2573.

81. Whiteley CM, Valle MD, Jones KC, Sweetman AJ. Challenges in assessing release, exposure and fate of silver nanoparticles within the UK environment. Environ Sci: Processes Impacts. 2013;15(11): 2050-2058.
International Journal of Nanomedicine

\section{Publish your work in this journal}

The International Journal of Nanomedicine is an international, peerreviewed journal focusing on the application of nanotechnology in diagnostics, therapeutics, and drug delivery systems throughout the biomedical field. This journal is indexed on PubMed Central, MedLine, CAS, SciSearch $®$, Current Contents $® /$ Clinical Medicine,

\section{Dovepress}

Journal Citation Reports/Science Edition, EMBase, Scopus and the Elsevier Bibliographic databases. The manuscript management system is completely online and includes a very quick and fair peer-review system, which is all easy to use. Visit http://www.dovepress.com/ testimonials.php to read real quotes from published authors.

Submit your manuscript here: http://www.dovepress.com/international-journal-of-nanomedicine-journal 